IZA DP No. 9862

How Do Households Discount over Centuries?

Evidence from Singapore's Private Housing Market

Eric Fesselmeyer

Haoming Liu

Alberto Salvo

April 2016 


\title{
How Do Households Discount over Centuries? Evidence from Singapore's Private Housing Market
}

\author{
Eric Fesselmeyer \\ National University of Singapore \\ Haoming Liu \\ National University of Singapore \\ and IZA \\ Alberto Salvo \\ National University of Singapore
}

Discussion Paper No. 9862

April 2016

IZA
P.O. Box 7240
53072 Bonn
Germany

Phone: +49-228-3894-0

Fax: +49-228-3894-180

E-mail: iza@iza.org

\begin{abstract}
Any opinions expressed here are those of the author(s) and not those of IZA. Research published in this series may include views on policy, but the institute itself takes no institutional policy positions. The IZA research network is committed to the IZA Guiding Principles of Research Integrity.

The Institute for the Study of Labor (IZA) in Bonn is a local and virtual international research center and a place of communication between science, politics and business. IZA is an independent nonprofit organization supported by Deutsche Post Foundation. The center is associated with the University of Bonn and offers a stimulating research environment through its international network, workshops and conferences, data service, project support, research visits and doctoral program. IZA engages in (i) original and internationally competitive research in all fields of labor economics, (ii) development of policy concepts, and (iii) dissemination of research results and concepts to the interested public.
\end{abstract}

IZA Discussion Papers often represent preliminary work and are circulated to encourage discussion. Citation of such a paper should account for its provisional character. A revised version may be available directly from the author. 


\section{ABSTRACT}

\section{How Do Households Discount over Centuries? Evidence from Singapore's Private Housing Market ${ }^{*}$}

We examine Singapore's fairly homogeneous private-housing market and show that new apartments on historical multi-century leases trade at a non-zero discount relative to property owned in perpetuity. Descriptive regressions indicate that new apartments with 825 to 986 years of tenure remaining are priced 4 to $6 \%$ below new apartments under perpetual ownership contracts that are otherwise comparable. We consider an empirical model in which asset value is decomposed into the utility of housing services and a second factor that shifts with asset tenure and the discount rate schedule. Exploiting the supply of new property with tenure ranging from multiple decades to multiple centuries, we estimate the discount rate schedule, restricting it to vary smoothly over time through alternative parametric forms. Across different specifications and subsamples, we estimate discount rates that decline over time and, accounting for the observed price differences, are of the order of $0.5 \%$ p.a. by year 400-500. The finding that households making sizable transactions do not entirely discount benefits accruing many centuries from today is new to the empirical literature on discounting and, with the appropriate risk adjustment, of relevance to evaluating climate-change investments.

JEL Classification: D61, G12, H43, Q51, Q54, R32

Keywords: discounting, social discount rate, declining discount rates, asset pricing, cost-benefit analysis, policy evaluation, long time horizon, climate change, real estate

Corresponding author:

Haoming Liu

Department of Economics

National University of Singapore

1 Arts Link

Singapore 117570

E-mail: ecsliuhm@nus.edu.sg

\footnotetext{
* We thank audiences at National ChengChi University, National University of Singapore, the Singapore Economic Review conference and, in particular, Sumit Agarwal, Adam Jaffe and Ivan Png for helpful comments. We are grateful to Maureen Cropper for alerting us to the existence of Giglio et al. (2015a)'s working paper examining UK and Singapore real estate, on approaching her at the "Discounting for the Long Run" session at the 2014 ASSA meetings to describe our work in progress studying discounting in the Singapore market.
} 


\section{Introduction}

Public policies generally have dynamic implications, and therefore the choice of how to discount costs and benefits that arise over time is critical. In some cases, the relevant horizon extends well beyond decades to include several centuries into the future. In particular, the economic analysis of climate change and the resulting mitigation policy recommendations rely heavily on the assumed structure of discount rates, as illustrated in the recent debate on the Stern Review (2007). Nordhaus (2007a,b) criticized the Review's use of a $1.4 \%$ per annum (p.a.) consumption rate of discount, low relative to the historical average return on capital, making distant damages from climate change loom larger and calling for sharp and immediate action. ${ }^{1}$ Weitzman (2007a) asserts that "what to do about global warming depends overwhelmingly on the imposed interest rate" (p.715). The US Office of Management and Budget (OMB) Circular A-4 recommends constant discount rates between $3 \%$ and $7 \%$ p.a. depending on whether the particular regulation mainly affects household consumption or firms' use of capital. Since at a $3 \%$ rate one dollar one century away is worth only 5 cents today, OMB (2003) prescribes "further sensitivity analysis using a lower but positive discount rate (in the presence of) important intergenerational benefits or costs." The Interagency Working Group on Social Cost of Carbon (2010) cites "ethical objections that have been raised about rates of $3 \%$ or higher" (p.23). ${ }^{2}$

Urged on by the climate-change policy debate, a growing body of theory addresses how consumption should be discounted over the very long run, suggesting that the discount rate should decline over time. ${ }^{3}$ In sharp contrast, there remains a dearth of evidence on how economic agents actually make trade-offs between today and the distant future, because markets for assets or claims with long-run maturities are rarely observed. Surveying the literature on declining discount rates (DDR), Groom et al. (2005) write: "The difficulty in the long run is the absence of financial assets

\footnotetext{
${ }^{1}$ See Stern and Taylor (2007) and, for an earlier debate, Cline (1992) and Nordhaus (1994).

${ }^{2}$ See also Greenstone et al. (2011), Stern (2013) and Sunstein (2014). Cropper et al. (2014) contrast discounting practices in the US, which adopts a flat discount rate schedule for cost-benefit analysis of public investment, to declining discount rates adopted by the governments of France, the UK, Norway, and Denmark.

${ }^{3}$ Summing up, the expert panel in Arrow et al. (2012) "agree that the Ramsey formula provides a useful framework for thinking about intergenerational discounting ... (and) also agree that theory provides compelling arguments for a declining certainty-equivalent discount rate." Theory models serial correlation or uncertainty in the consumption growth rate (Gollier, 2002, 2008, 2014; Weitzman, 2007b) or in the discount rate (Weitzman, 1998, 2001; Gollier and Weitzman, 2010). Nordhaus (2007b) argues that modeling uncertainty in preferences is "largely unchartered territory in economic growth theory" (p.693). A descriptive (positive) approach approximates the discount rate at a level between the empirically observed return-on-equity and risk-free market rates, depending on the assumed degree to which climate-change damages and aggregate economic activity correlate (Weitzman, 2007a, 2013). Surveying 200 academic experts, Drupp et al. (2015) find that "those who place more emphasis on market-based rates of return recommend higher social discount rates" (p.17).
} 
whose maturity extends to the horizon associated with... global warming. Government bonds, for example, do not extend beyond 40 years in general" (p.465).

A recent paper is able to break new ground. Giglio, Maggiori and Stroebel (2015, GMS hereafter) examine residential housing markets in the UK and in Singapore. Property ownership in these markets take the form either of freeholds, in which the right to the property is held in perpetuity, or of leaseholds, in which the property right reverts to the freeholder, such as the government, following long to very-long initial horizons of 99 to 999 years. By comparing transaction prices across freeholds and leaseholds, or within leaseholds of varying remaining tenure - properties that are assumed to be otherwise comparable - GMS infer whether households today value differential benefits that accrue from the date of leasehold expiry, say 100 or 1000 years from today.

GMS find that "100-year leaseholds are valued 10-15\% less than otherwise identical freeholds; leaseholds with maturities of 125 to 150 years are valued 5-8\% less than freeholds. There are no price differences between leaseholds with maturities of more than 700 years and freeholds." (p.3) To obtain such results, GMS group properties of similar-yet different-remaining lease length into groups, e.g., 80-99, 100-124, ..., 150-300, and 700+ years (Table III, UK flats). The authors then estimate the co-variation of purchase prices with dummy variables for the different groups, from ordinary least squares (OLS) regressions that include hedonic control variables.

This paper makes two key advances over GMS. First, focusing on Singapore, we obtain precisely estimated non-zero price differences, of 4 to $6 \%$, between leaseholds with maturities of about 900 years and freeholds. The result is important and policy-relevant. If households significantly value freeholds above and beyond "very long run" leases, that is, if utility starting nine centuries from today is not entirely discounted, then discount rates dip below $0.5 \%$ p.a. by year $400-500$, as we show. This finding is new to a sparse empirical literature, and suggests that payoffs in the far-distant future are valued more than reported previously for a similar asset horizon and risk. ${ }^{4}$

This new finding for Singapore is due mainly to the way we control for location effects and our use of an arguably more homogeneous sample. GMS, whose primary focus is the UK housing

\footnotetext{
${ }^{4} \mathrm{~A}$ few other studies have used price differences across properties of varying lease lengths to estimate discount rates. Examining small residential lots in Hawaii, Fry and Mak (1984) estimate a discount rate of $11 \%$ p.a.. Wong et al. (2008) infer a discount rate of $4 \%$ p.a. from Hong Kong housing data. Gautier and van Vuuren (2014) estimate a model of quasi-hyperbolic discounting with house sales in Amsterdam, finding a first-year discount rate of $20 \%$ and a discount rate of $1.9 \%$ p.a. thereafter. Bracke et al. (2015), using house and flat sales in Central London, nonparametrically estimate discount rates that decline from 5-6\% for nearly expired leaseholds to $3-4 \%$ for leaseholds with nearly a hundred years remaining. These papers differ from ours and GMS in that they all estimate discount rates over shorter horizons (99 years or fewer) than we consider.
} 
market ${ }^{5}$ grouped properties with the same first five digits of Singapore's six digit postal (zip) code to assign geographic fixed effects. Five-digit zip codes in the city-state, where each apartment building is assigned its own individual six-digit zip code, control for location very finely, yet they remove much of the variation in land lease contracts. In a sample of 1,672 unique development projects - collections of adjacent high-rise buildings, sharing a land parcel and a street entrance, that form the bulk of the Singapore sample - controlling for five-digit zip code introduces 1,516 fixed effects. Thus, much of the price variation that is driven by tenure is captured by these highly granular fixed effects. Residual co-variation in price and tenure can arise from including used property sales in the sample, in which remaining tenure and age co-vary quite mechanically (within project, an additional year of age implies a year less of lease).

In contrast, we adopt less granular yet still highly detailed geographic controls, grouping buildings by the first three digits of the zip code. Given Singapore's small land area, including 187 three-digit zip code fixed effects adequately controls for locational price differences in our sample. Over $95 \%$ of development project pairs with a common three-digit zip code are located in an area with a $0.9 \mathrm{~km}$ radius. Moreover, we focus on newly constructed property sold between 1995 and 2015, rather than a combination of new and used properties as GMS do. We control for additional characteristics such as floor number, and account for the fact that most new property purchases occur - and payments begin - a few years before construction is completed. We also exclude comparatively heterogeneous detached and semi-detached houses that are sold to qualifying buyers, that GMS included in their sample. ${ }^{6}$ As a result, we are able to attain estimation precision. Our differential finding relative to GMS, of a positive premium for freehold property over multi-century leases, begs the question as to its source. Thus, to the best of our ability, in Appendix A.5 we reproduce the GMS sample, then proceed to estimate and compare specifications from GMS against those we judge to be more appropriate to the Singapore real estate market.

The second key advance over GMS is that we take a more structural approach and use the entire variation in lease length in our sample of new properties purchased by households at market prices to directly estimate the schedule of discount rates up to one millennium from today. Using nonlin-

\footnotetext{
${ }^{5}$ We do not study the UK, and the comments that follow do not apply to the excellent UK analysis GMS provide. Future work may examine why we find a positive discount for multi-century leases over freeholds in Singapore whereas GMS do not for the UK.

${ }^{6}$ Table VI, column (6) in GMS, using a sub-sample of 45,084 (new and used) detached and semi-detached houses, illustrates this point: GMS find no statistically significant discounts for 90-94 and 95-99 year leaseholds relative to freeholds, and the point estimate for the 95-99 year lease discount exceeds the estimated discount for the shorter 90-94 year leases by 3 percentage points.
} 
ear least squares (NLLS) and alternative assumptions on how unobservables enter the estimating equation, our preferred specification fits a smoothly varying exponential form to the discount rate as a function of time. Discount rates are about $4 \%$ (p.a.) up to year 10 , fall to $3 \%$ by year 100 , thereafter dropping to $0.5 \%$ by year $400-500$ and $0.2 \%$ by year 700 . This empirical schedule is robust to sample composition. Across different functional forms for how the discount rate evolves over time, we estimate declining discount rates (DDR). The approach is simple, transparent, and thus appealing. ${ }^{7}$

In the remainder of the paper, Section 2 discusses the institutions and the data. Section 3 develops the empirical model and describes the estimation algorithm. Section 4 reports estimates from both descriptive and structural regressions. Section 5 concludes, comparing our estimated discount rate schedule to schedules that are effective in policy today.

\section{Institutional background and data}

\subsection{Background}

The residential housing market in Singapore consists of three types of properties: (i) apartments in high-rise buildings developed by Singapore's public housing authority, the Housing and Development Board (HDB), (ii) apartments in buildings, often high-rise, developed by private companies, and (iii) detached and semi-detached houses, which are also developed by private companies. New HDB apartments are sold only to Singaporean citizens, and at subsidized prices. Privately developed apartments are sold to both Singaporeans and foreigners, at market prices. Following local practice, we refer to these privately developed apartments, as opposed to HDB apartments, as condominiums. Detached and semi-detached houses, known as landed properties, are sold to citizens and sometimes, with permission from the Singapore Land Authority, a government agency, to permanent residents and foreigners.

According to Singapore Department of Statistics (2015), there are 1.3 million housing units in Singapore, and home ownership among households headed by a citizen or permanent resident is a high $90 \%$. Of these 1.3 million units, $75.1 \%$ are HDB apartments, $18.3 \%$ are condominiums (again, taken to mean all privately developed apartments), 5.7\% are detached or semi-detached houses,

\footnotetext{
${ }^{7}$ We model the "certainty-equivalent discount rate" in reduced form, but in principle the approach is amenable to imposing restrictions from a structural model of discounting embedded in an asset pricing or growth model, that additionally models uncertainty.
} 
and $0.9 \%$ are other unclassified properties. We choose to examine transactions of condominiums, as their purchases are not subsidized or restricted. ${ }^{8}$ To control for aging, we also focus our sample on purchases of new, rather than new and used, properties. Our sample consists of new condominium purchases over the January 1995 to January 2015 period. We argue below that property characteristics of new condominiums exhibit quasi-experimental variation that we can most credibly exploit. We also contrast this with the sample GMS use in the Singapore part of their study, namely, new and used condominiums as well as detached/semi-detached house purchases between 1995 and 2013.

Singapore residential property ownership comprises freehold estates and leasehold estates. Freeholds are assets owned in perpetuity, in contrast to leaseholds, in which the land and the housing infrastructure built on the leased land revert to the lessor - typically the state - when the lease expires. The origin of this land tenure system dates back to the early 1800s when Singapore was under British colonial rule (Lornie, 1921). Pursuant to the Letters Patent issued on November 27, 1826, English law and with it the land title system became the basis of the land law in Singapore (Taylor Wessing, 2012). Much of the land that was developed over the 19th and much of the 20th centuries was in the form of freeholds and, to a lesser extent, leaseholds with typical initial tenure of 999 years. The tenure remaining on these original 999-year leases that survived to our 1995-2015 sample period ranges from 825 to 986 years. In practice, developers acquire rights to these lands, build new condominiums on them, and sell them to households at their remaining tenure, 875 years say. We label such assets with "very long run" maturities "999-year leaseholds," and in the structural analysis we characterize them by their exact remaining tenure.

Following independence in 1965, the government embarked on a large-scale program to buy back some of the land that was privately held. ${ }^{9}$ By the 1990s, and following the 1992 State Lands Act in particular, a 99-year term had become the norm for state-leased land, whether for new development or redevelopment, by the housing authority and private developers alike. In sum, the majority of condominiums built on land released by the government in the past two decades have tenure of 99 years from the date a property developer acquired the rights - properties we label "99-

\footnotetext{
${ }^{8}$ Appendix A.6 describes some of the restrictions on HDB purchases and discusses how taxes on acquiring and holding property vary by residency status and the number of properties owned.

${ }^{9}$ The objective was partly to develop public housing through the HDB and partly to redevelop derelict areas. By 1984, the government had acquired a total of 177 square $\mathrm{km}$ of land, enabled by parliament's passing of a Land Acquisition Act in 1966 (Aleshire, 1986). The government also increased its land holdings by reclaiming land from the sea. By 2010, Singapore's land area reached 712 square $\mathrm{km}$ compared to 586 square $\mathrm{km}$ some decades earlier, $90 \%$ of which is government-owned (Phang and Kim, 2011).
} 
year leaseholds." In contrast, the majority of condominiums built on privately owned land, whose titles were often issued by the British colonial governments, are either freeholds or leaseholds with more than 900 years of lease remaining.

History has thus shaped a unique residential market in which newly developed condominium projects under widely varying ownership tenure - ranging from perpetuities to multi-century maturities to multi-decade maturities - are located in close proximity, both in space and in time. By project, we refer to a collection of adjacent buildings, each with many housing units, sharing a land parcel, a name - e.g., "The Anchorage" — and facilities such as a common street entrance and fence. ${ }^{10}$ Figure 1 depicts the location of all new condominium projects with sales of new units between 1995 and 2015, shown separately by 5-year intervals. Each triangle, square, or circle represents a freehold project, a 999-year leasehold project, and a 99-leasehold project, respectively. For perspective, the Central Business District is marked by a star (One Raffles Place), though we note that a wide radius around Singapore's downtown area is densely urbanized.

The figure illustrates a key feature of the data: wherever and whenever the sale of a new condominium under one tenure type took place, the sale of another new condominium under a different tenure type also tended to occur. Close inspection reveals that this is particularly the case for freeholds and 999-year leaseholds, consistent with their shared colonial history. Also, due to the land acquisition program, granular markets that house new freehold and 999-year leaseholds tend to also house new 99-year leaseholds too. This feature enables us to identify the effect of tenure length on value, and thus the discount rate schedule, separately from the effect of location (e.g., comparing projects up to $1 \mathrm{~km}$ apart) and time (e.g., for a given state of the economy). The figure further confirms that "greenfield" projects, on government land assigned only in recent decades for residential development, have tended to be 99-year leaseholds - see the more scattered, peripheral parts of the city-state, such as the northeast, that house relatively more projects on 99-year leases. For this reason, we complement our analysis of the full sample by considering subsamples of geographic markets with a similar presence of freeholds and 999-year leaseholds, or a similar presence of all three tenure types.

As in GMS, our maintained assumption regarding respect for contracts-namely, that lessees enjoy the right to full term on their assets prior to the lessor taking over-implies that the residual value of leasehold properties is zero at the end of the land tenure. ${ }^{11}$ It is then reasonable to assume

\footnotetext{
${ }^{10}$ Conditional on project, tenure type is invariant, e.g., a 999-year lease originally issued in the 19th century.

${ }^{11}$ The Singapore Land Authority states that "(i)n general, the Government's policy is to allow leases to expire
} 
that the reason households pay a premium for freehold properties over similar 999- or 99-year leasehold ones is that the former generates a longer utility stream. In particular, the purchase of properties whose lease expires in over 800 years alongside the purchase of freeholds that are otherwise comparable allows us to infer whether households today value benefits accruing many hundreds of years into the future.

\section{$2.2 \quad$ Data}

We extract housing transaction data from the Urban Redevelopment Authority's (URA) Real Estate Information System (REALIS) for the period of January 1995 to January 2015. REALIS contains information on all private residential property transactions with a lodged caveat. ${ }^{12} \mathrm{~A}$ caveat is a legal document lodged with the Singapore Land Authority by a buyer or the mortgage provider to register the buyer's legal interest in the property. While filing a caveat is not mandatory, nearly every buyer does so, and the REALIS database contains information on nearly the universe of new condominium transactions. According to URA, the stock of condominiums increased by 183,845 units from 53,429 in the fourth quarter of 1994 to 237,274 in the fourth quarter of 2014 . In comparison, the REALIS transaction database contains 179,505 new sale records with 214 of them multi-unit transactions, including one multi-unit purchase of 80 units. We drop these relatively few multi-unit records as they do not contain characteristics of the individual transacted units.

Unlike GMS who examined transactions of both new and used condominium units, we only use the former. The reason for doing so is that it may be difficult to separately identify the effect of age and the number of lease years remaining, as these two variables are perfectly correlated as units in an existing building grow older. Focusing on new property should allow us to better control for the unobserved quality of the traded units. Presumably, the quality of used units traded with identical observed characteristics could differ considerably due to maintenance and depreciation. In contrast, the quality differences among new units sold by a developer are likely to be small.

We observe the date on which the unit was transacted (the "Sales \& Purchase Agreement" is signed), the purchase (transaction) price, the year building construction was completed (the "Temporary Occupation Permit" is granted), the initial duration of land tenure, and the date on

without extension" (extracted from http://www.sla.gov.sg/htm/new/new2008/new0109.htm on October 11, 2014). An exception is sometimes made in the case of "en bloc" sales. A developer who seeks to acquire aging property en bloc from homeowners, on ongoing yet unexpired 99-year leases, to be torn down and developed anew, can request from the government, for a fee, a "top up" to a 99-year lease.

${ }^{12}$ Caveats are lodged for over 9 in every 10 transactions. Appendix A.1 details our sample coverage. 
which tenure was originally granted. For example, one observation pertains to the purchase of a condominium on 4/4/2008 (the unit's contract date) for $\mathrm{S} \$ 2,817,000$, with construction completed in 2007 and a lease of "998 Yrs From 27/12/1875." For this transaction, we compute the remaining tenure at the date of purchase to be 998-(2008-1875)=865 years. We also observe the unit's address, from which we extract the unit's floor number and the six-digit unique postal (zip) code associated with the building, the unit's size in square meters, and the condominium project's name. For projects with missing completion year, we collected completion years from several real estate websites. ${ }^{13}$ We failed to find the completion year for 19 units; we exclude these from our analysis. We also exclude 28 transactions that are basement units or have missing floor number, and another 26 units sold 11 years after construction was completed, transactions that likely relate to used units. Our final sample consists of 179,218 units (99.9\% of the 179,505 new sale records in REALIS), pertaining to 1,672 unique development projects.

Our empirical analysis requires that we take a stand on the granularity at which to control for unobserved spatial heterogeneity. If geographic controls are too coarse, our estimates of the effect of tenure on value might be confounded by omitted geographic determinants of prices; too fine the geographic controls and these might subsume precisely the variation in remaining tenure that we seek to exploit. For example, six-digit zip codes perfectly predict the condominium building, and in most cases the first five digits of the zip code perfectly predict the development project (collection of adjacent buildings), there being no variation in tenure within a building or project.

As discussed in Appendix A.2, we include 187 fixed effects to account for geographic variation at the three-digit zip code level. Figure 2 plots the distribution of bilateral distances for each pair among the 1,672 projects that share the same three-digit zip code. Specifically, $75 \%$ of these bilateral distances are shorter than $1 \mathrm{~km}$ and $95 \%$ of the distances are shorter than $1.8 \mathrm{~km}$. In other words, $95 \%$ of project pairs with a common three-digit zip code are located in an area with a $0.9 \mathrm{~km}$ radius. Together, Figures 1 and 2 illustrate why our geographic controls offer a good compromise between controlling for potentially confounding spatial heterogeneity and allowing enough residual variation in tenure type (that is orthogonal to building age, another determinant of prices).

We adjust nominal purchase prices to account for variation in the Consumer Price Index (Singapore Department of Statistics CPI), converting transaction prices to January 2014 dollars. We

\footnotetext{
${ }^{13}$ We complete missing construction completion year in the REALIS data-typically associated with units that were sold prior to completion of construction - with data from three major websites, propertyguru.com.sg, iproperty.com.sg, and stproperty.sg.
} 
commonly observe units being sold during construction. For transactions that pre-date construction completion, the median time between when the unit is purchased and when construction is completed is three years. In these cases, buyers follow a graduated schedule of partial payments until construction is completed and the keys are handed over, at which time the remaining balance is due in full, and the flow of housing benefits begins. Where a condominium purchase occurs during construction, we follow a typical payment schedule and use the CPI to adjust (compound) the prepaid components of the purchase price to the time construction is completed, as detailed in Appendix A.3. Intuitively, making partial payment on a property years before it is delivered and housing services can begin is akin to paying a higher price when the property is delivered. Further, to allow for unobserved heterogeneity (the best offerings "sell like hotcakes"), our empirical analysis flexibly controls for the time between condominium purchase and construction completion, using one-year bins from the negative to the positive domain.

In such cases in which transactions occur prior to construction being completed, we take the time between construction completion (not transaction) to lease expiry for the purpose of calculating the remaining asset life. For example, another observation in the data documents the purchase of a unit on 2/11/2008 for $\$ \$ 1,301,206$ (a condominium about half the size of the one in the previous example), with construction completed in 2011, and a leasehold of "999 Yrs From 21/06/1877." For this example, we compute the remaining years of tenure as 999-(2011-1877)=865 years.

Panel A of Table 1 summarizes the density of remaining tenure against transaction year across the full sample of 179,218 purchases. We also summarize two subsamples, based on geographic location, that we will use throughout to verify the robustness of our findings: we restrict the sample of purchases to three-digit zip codes where both 825 to 986-year leases and freeholds were traded (31,072 purchases), or restrict to three-digit zip codes where all three tenure types were traded (22,751 purchases). In these subsamples, the ratio of original 999-year leaseholds to freeholds is considerably higher, at about $40 \%$, than in the full sample, as these areas are located in the more established parts of Singapore (Figure 1). We group the joint density into cells of similar length only for ease of exposition. Overall, the number of new condominiums sold across Singapore has grown in the last decade; growth in the more established areas has been less marked. Trade in new freehold units has also grown. With the passing of time, the proportion of new units with 876 to 986 years of lease remaining has fallen while the proportion of leaseholds with 825 to 875 remaining years has risen. The data indicates (but, for brevity, not the table) that new parcels 
of land issued on 99-year leases were developed quickly: for 99-year leases granted since 1991, the median development time to construction completion is 4 years.

Panel B further describes the data. For example, the mean unit size and purchase price are, respectively, $108 \mathrm{~m}^{2}$ and $\mathrm{S} \$ 1.4$ million, in January 2014 dollars, or roughly US $\$ 1$ million. Averaged across observations, the number of neighboring units within the same development project is 370 , and $70 \%$ of units belong to projects developed on land parcels that the URA data classifies as large (at least 0.4 hectare). One also sees the large variation in building heights in Singapore. The average building contains 9 floors, with low-rises of a single floor up to high-rises of 70 floors. These observed characteristics, along with others, are potential value shifters that we control for.

\section{Conceptual framework}

We specify condominium $i$ 's time-invariant flow utility from housing services, $u_{i}$, as shifting with property characteristics, $X_{i}$, such as the size of the unit, the floor it is on, and its detailed geographic location, e.g., three-digit zip code:

$$
u_{i}=u\left(X_{i} ; \theta\right)
$$

where $\theta$ is a row vector of parameters to be estimated. We lay out the empirical model in discrete time, thus $u_{i}$ is the value of housing services per year, valued at the start of that year. Index the first year in which these benefits accrue to the buyer by $t=1$. Housing benefits accrue over a finite tenure of $T_{i} \in[2, \infty)$ years if the property is a leasehold, or in perpetuity if it is a freehold, and are modelled as certain. The other primitive in the model is the schedule of certainty-equivalent annual discount rates (Weitzman, 1998), $r_{t}>0$, which can vary over time and on which we subsequently impose alternative structures. The sum of discounted value of the finite or infinite utility stream at the moment the buyer takes ownership of the asset (and building is complete) is:

$$
V_{i}=V\left(X_{i}, T_{i} ; \theta, \mathbf{r}\right)=\left\{\begin{array}{l}
u\left(X_{i} ; \theta\right)\left(1+\sum_{t=2}^{T_{i}<\infty} \frac{1}{\prod_{s=1}^{s=t-1}\left(1+r_{s}\right)}\right) \text { if } i \text { is a leasehold } \\
u\left(X_{i} ; \theta\right)\left(1+\sum_{t=2}^{\infty} \frac{1}{\prod_{s=1}^{s=t-1}\left(1+r_{s}\right)}\right) \text { if } i \text { is a freehold }
\end{array}\right.
$$

where $\mathbf{r}=\left(r_{1}, r_{2}, \ldots\right)$ and $T_{i} \in[2, \infty]$ (the upper bound of the interval is now closed, to include the freehold case). Thus, for example, the present value of housing services in the first, second 
and third periods are $u_{i}, u_{i}\left(1+r_{1}\right)^{-1}$ and $u_{i}\left(1+r_{1}\right)^{-1}\left(1+r_{2}\right)^{-1}$, respectively (by present value we mean valued at the start of $t=1$ ). As modelled, the discount rate $r_{t}$ discounts benefits from year $t+1$ to year $t$; it is a "forward rate," as in, e.g., Arrow et al. (2014).

The transaction price of the property, $p_{i m}$, is given by the underlying value, $V_{i}$, scaled by an exponential function of the sum of two unobservable shocks: a shock that varies across transactions but is common to the market $m$ in which the transaction took place, denoted $\xi_{m}$; and an idiosyncratic mean-zero shock to the transaction of property $i$ in property market $m$, denoted $\varepsilon_{i m}$ :

$$
p_{i m}=V\left(X_{i}, T_{i} ; \theta, \mathbf{r}\right) e^{\xi_{m}+\varepsilon_{i m}}
$$

The market effect $\xi_{m}$ may be due, for example, to the business cycle (the state of the economy) and to seasonality, to be captured by year fixed effects and quarter-of-year fixed effects, respectively.

Identification follows from the fact that the value function factors into flow utility of housing services, that shifts with property characteristics, and a second factor that shifts with tenure and the discount rate schedule. Denote this second factor - the discounted sum of a tenured stream of unitary flows - by the "discounted tenure" function:

$$
\phi\left(T_{i} ; \mathbf{r}\right):=1+\sum_{t=2}^{T_{i} \in[2, \infty]} \frac{1}{\prod_{s=1}^{s=t-1}\left(1+r_{s}\right)}
$$

and thus the value function is:

$$
V\left(X_{i}, T_{i} ; \theta, \mathbf{r}\right)=u\left(X_{i} ; \theta\right) \phi\left(T_{i} ; \mathbf{r}\right)
$$

$\phi\left(T_{i} ; \mathbf{r}\right)$ can be interpreted as the asset's "price multiple," a price-flow utility ratio (short of the deviates).

From the assumption on unobservables, we derive the loglinear estimating equation:

$$
\ln p_{i m}=\ln u\left(X_{i} ; \theta\right)+\ln \phi\left(T_{i} ; \mathbf{r}\right)+\xi_{m}+\varepsilon_{i m}
$$

Alternatively, the relationship between the transaction price and underlying value, i.e., (1), can 
be specified with additively separable errors, providing a variant on the estimating equation:

$$
\begin{aligned}
p_{i m} & =V\left(X_{i}, T_{i} ; \theta, \mathbf{r}\right)+\xi_{m}+\varepsilon_{i m} \\
& =u\left(X_{i} ; \theta\right) \phi\left(T_{i} ; \mathbf{r}\right)+\xi_{m}+\varepsilon_{i m}
\end{aligned}
$$

It is clear that by comparing the price of a freehold $j$ to that of a $T_{i}$-year leasehold property $i$, with otherwise identical property characteristics, $X_{i}=X_{j}=X$, and traded in the same market $m$, i.e.,

$$
p_{j m}-p_{i m}=u(X ; \theta)\left(\sum_{t=T_{i}+1}^{\infty} \frac{1}{\prod_{s=1}^{s=t-1}\left(1+r_{s}\right)}\right)+\varepsilon_{j m}-\varepsilon_{i m}
$$

we can learn about the schedule of discount rates as we vary $T_{i}$ :

$$
E\left[p_{j m}-p_{i m}\right]=u(X ; \theta)\left(\sum_{t=T_{i}+1}^{\infty} \frac{1}{\prod_{s=1}^{s=t-1}\left(1+r_{s}\right)}\right)
$$

This expected "freehold premium" is the present value of housing services beginning in year $T_{i}+1$. Thus, the price difference between a freehold condominium unit and a unit with a remaining tenure of 875 years (but otherwise identical in characteristics) can be interpreted as the value, discounted to present day dollars, of housing services beginning 876 years from today.

One can see from the estimating equations that the variation in $\phi\left(T_{i} ; \mathbf{r}\right)$ across properties provides a measure of the transaction price variation in the data that is explained by differences in tenure valued from the present day. Thus, a unit with a remaining tenure of 875 years should trade at an expected discount of $1-\phi\left(T_{i}=875 ; \mathbf{r}\right) / \phi\left(T_{i} \rightarrow \infty ; \mathbf{r}\right)$ relative to a comparable freehold. A unit with a remaining tenure of 94 years should trade at a $1-\phi\left(T_{i}=94 ; \mathbf{r}\right) / \phi\left(T_{i} \rightarrow \infty ; \mathbf{r}\right)$ discount relative to a comparable freehold. Fixing property and market characteristics, $X_{i}$ and $\xi_{m}$, it is this co-variation between remaining tenure and transaction prices that reveals how households discount over the very long run, namely, many centuries into the future.

Notice that if discount rates do not vary over time, $r_{t}=r, \phi($.$) collapses to:$

$$
\phi\left(T_{i} ; r\right):=\sum_{t=1}^{T_{i} \in[2, \infty]} \frac{1}{(1+r)^{t-1}}=\left(1-\left(\frac{1}{1+r}\right)^{T_{i}}\right) /\left(1-\frac{1}{1+r}\right)
$$

The empirical model can be implemented with different forms for the discount rate schedule, 
including microfounded structures, derived from theory. Let vector $\gamma$ parameterize the discount rate schedule, so we can write $r_{t}=r(t ; \gamma)$ and $\mathbf{r}=r(\gamma)$.

\subsection{Estimation algorithm}

Equations (2) and (3) can be estimated by nonlinear least squares (NLLS). Specifically, we respectively solve:

$$
\begin{gathered}
\underset{\gamma, \theta, \xi}{\operatorname{argmin}} \sum_{i=1}^{N}\left(\ln p_{i m}-\ln u\left(X_{i} ; \theta\right)-\ln \phi\left(T_{i} ; \mathbf{r}\right)-\xi_{m}\right)^{2} \quad \text { (log.lin.) } \\
\left.\underset{\gamma, \theta, \xi}{\operatorname{or}, \underset{i=1}{\operatorname{argmin}}} \sum_{\text {subject to } \mathbf{r}=\left(r_{1}(\gamma), r_{2}(\gamma), \ldots\right)>0}^{N}\left(p_{i m}-u\left(X_{i} ; \theta\right) \phi\left(T_{i} ; \mathbf{r}\right)-\xi_{m}\right)^{2} \quad \text { (add.sep. }\right) \\
\end{gathered}
$$

where we collect all market fixed effects in a row vector $\xi=\left(\xi_{m}\right)$. The constrained optimization searches for parameters that minimize, across the $N$ properties in the sample, the sum of squared residuals. The key primitive of interest is the discount rate schedule, $\mathbf{r}=\left(r_{1}, r_{2}, \ldots\right)$, which we can allow to vary over time either parametrically or non-parametrically. (For notational convenience, in the remainder of this section we omit the rate schedule parameters $\gamma$ from $\mathbf{r}$.)

Notice that with additively separable errors (3), if we further specify flow utility as linear in parameters, $u\left(X_{i} ; \theta\right)=X_{i} \theta$, then we have:

$$
p_{i m}=\phi\left(T_{i} ; \mathbf{r}\right) X_{i} \theta+\xi_{m}+\varepsilon_{i m} \quad \text { (add.sep. \& lin.util.) }
$$

Fixing $\mathbf{r}$, this equation is linear in the remaining parameters, $\theta, \xi_{m}$ : these need not be included in the nonlinear search. To see this, express the scalar $\xi_{m}$ as $\xi D_{i}^{\prime}$, where $D_{i}$ is a row vector of market dummies (year and quarter) for property $i$, stack all observations, and use matrix notation to write: ${ }^{14}$

$$
\begin{aligned}
p & =\left[\begin{array}{ll}
\phi(T ; \mathbf{r}) X & D
\end{array}\right]\left[\begin{array}{ll}
\theta & \xi
\end{array}\right]^{\prime}+\varepsilon \\
& =Z(\mathbf{r}) \alpha+\varepsilon
\end{aligned}
$$

\footnotetext{
${ }^{14}$ We abuse notation by writing $\phi(T ; \mathbf{r}) X$, meaning we multiply every $N \times 1$ column in $X$ by the $N \times 1$ column vector $\phi(T ; \mathbf{r})$, element by element. The columns of matrix $Z$ that pertain to property characteristics $X$ (resp., property market indicators $D$ ) are simply $X$ (resp., $D)$ scaled up by $\phi(T ; \mathbf{r})$, the "discounted tenure" function. The columns of matrix $Z$ that pertain to property market indicators $D$ are not scaled up.
} 
where $Z(\mathbf{r}):=\left[\begin{array}{ll}\phi(T ; \mathbf{r}) X & D\end{array}\right]$ and vector $\alpha=\left[\begin{array}{ll}\theta & \xi\end{array}\right]^{\prime}$ contains flow-utility parameters and property-market shocks. The function to be minimized, the sum of squared residuals, is then:

$$
(p-Z(\mathbf{r}) \alpha)^{\prime}(p-Z(\mathbf{r}) \alpha)
$$

In this case, the first-order condition with respect to $\alpha$ is linear in $\alpha$, so during estimation the $\theta$ and $\xi$ parameters can be "concentrated out":

$$
\alpha(\mathbf{r})=\left(Z(\mathbf{r})^{\prime} Z(\mathbf{r})\right)^{-1} Z(\mathbf{r})^{\prime} p
$$

and the optimization routine can search over the rate schedule (parameters):

$$
\underset{\gamma}{\operatorname{argmin}}(p-Z(\mathbf{r}(\gamma)) \alpha(\mathbf{r}(\gamma)))^{\prime}(p-Z(\mathbf{r}(\gamma)) \alpha(\mathbf{r}(\gamma))) \quad \text { (add.sep. \& lin.util.) }
$$

\section{Results}

\subsection{Descriptive analysis of value in the very long run}

We begin by regressing the logarithm of the transaction price per square meter of floor area (in January 2014 dollars) on indicator variables for the different ranges of remaining tenure, as well as other determinants of asset prices - see Table 2. Columns (1) to (3) consider the full sample of new condominium purchases by households between January 1995 and January 2015. The omitted category in columns (1) to (3) are freehold properties, so the estimated coefficients on the leasehold dummies should be interpreted as price discounts (in log points) relative to assets owned in perpetuity, that are otherwise comparable with regard to property characteristics and were purchased under the same market conditions. Besides the leasehold dummies, which are the main variables of interest, column (1) includes market fixed effects, namely year fixed effects (e.g., 1995) and quarter fixed effects (e.g., quarter 1), besides unit size in $\mathrm{m}^{2}$ and floor number (both entering in logs). Column (2) adds a full set of three-digit zip code fixed effects. Recall that $95 \%$ of project pairs with a common three-digit zip code are located in an area with a $0.9 \mathrm{~km}$ radius. The granular location intercepts raise the predictive power of the OLS regression to $85 \%$, compared to $48 \%$ in column (1) - the fixed effect for land parcels classified as large by URA, while positive, adds only $0.1 \%$ to the $\mathrm{R}^{2}$. Column (3) adds further controls, described below. 
The key and novel finding is that households still significantly value freeholds above and beyond very long run assets: value about 900 years into the future is not entirely discounted. Units with a remaining tenure of 825 to 986 years are still traded at a 0.038 price discount in log points, or about $3.7 \%$, relative to units offering comparable housing services over the same very long horizon as well as beyond. This finding is new to the empirical literature on discounting.

In column (4), we consider a subsample that includes original 999-year leaseholds and freeholds only, thus dropping original 99-year leaseholds. For this subsample, the value today of utility beginning as far as eight to nine centuries from today is estimated to be even higher than in the full sample: original 999-year leaseholds trade at a discount of $0.060 \mathrm{log}$ points, or $5.8 \%$, relative to freeholds, implying that households are very patient. For perspective, if discount rates are restricted to not vary over time, $r_{t}=r$, one can back out a discount rate of $0.33 \%$ per annum (p.a.) from this $5.8 \%$ transaction price discount of original 999 -year leaseholds to freeholds. ${ }^{15}$

In columns (5) and (6), we restrict the sample to purchases in three-digit zip codes with availability of: (i) both freeholds and 999-leaseholds (besides possibly 99-year leaseholds), and (ii) all three tenure types - recall the composition of these subsamples in Table 1. The 825 to 986-year leasehold discount relative to freeholds is estimated at 0.050 to $0.061 \log$ points.

Across columns (3), (5) and (6), properties with 87 to 99 years of remaining tenure trade at a discount of 0.155 to $0.199 \log$ points, or 14 to $18 \%$, relative to freeholds. For perspective, a unit with $T_{i}=94$ years of remaining tenure trading at a $14 \%$ discount to comparable freeholds (column (3) estimate) implies, in a model with constant discount rates, that $r=2.1 \%$ p.a.; the implied constant discount rate is slightly lower at $r=1.8 \%$ p.a. for an $18 \%$ discount of $87-99$ year leaseholds to freeholds (column (5) estimate). Properties with 56 to 63 years of remaining tenure trade at a discount of $0.343 \log$ points, or $29 \%$, relative to freeholds. A unit with, say, $T_{i}=60$ years trading at a $29 \%$ discount to freeholds implies, with constant discount rates, $r=2.1 \%$ p.a.. These rates of 1.8 to $2.1 \%$ are comparable, if somewhat lower in terms of point estimates, than the "discount rate for real estate cash flows 100 or more years in the future (of) about 2.6\%" (Giglio et al, 2015b, p.2).

\footnotetext{
${ }^{15} \mathrm{~A} 5.8 \%$ price discount follows from $1-e^{-.06} \simeq 0.058$. The implied constant discount rate $r$ from a unit with $T_{i}=860$ years of remaining tenure (999 years originally) trading at such a price discount to comparable freeholds follows from noting that:

$$
\left\{\begin{array}{c}
p_{860}=p_{\text {freehold }}\left(1-\frac{1}{(1+r)^{860}}\right) \\
p_{860} / p_{\text {freehold }} \simeq e^{-.06}
\end{array}\right.
$$
}

which solves for $r \simeq 0.0033$. 
We also note from Table 2 that a condominium's price per $\mathrm{m}^{2}$ tends to decrease in size (floor area) and increase in floor number. Since units on the top floor of the building tend to have a larger recorded size, e.g., less valuable external balcony space that depresses the price per $\mathrm{m}^{2}$, we include an indicator for such properties. We note below that our results are robust to dropping such top-floor properties from the sample. Since we include log size as a regressor, regressions reported in Table 2 are akin to regressions using the log of price (rather than the log of price per $\mathrm{m}^{2}$ ) as the dependent variable, in which case the estimated coefficient on log size in the full sample would be about 0.9 - a $1 \%$ increase in unit size raises the price by $0.9 \%$. Properties that are sold prior to the year construction is completed also command a higher price (not shown for brevity).

Robustness. Panel A of Table A.1 ("functional form") repeats the regressions shown in columns (3) to (6) of Table 2 but, in terms of controls, replaces the logarithms of unit size, floor number and development project size by quadratic functions of each of these property characteristics. Estimates are very robust to these changes. The coefficient on the first-floor dummy is significantly negative under this variation in functional form - we note below that estimates on tenure type are also robust to flexibly allowing for a full set of floor-level intercepts.

Panel B of Table A.1 again repeats regressions (3) to (6) of Table 2 but takes the purchase price per $\mathrm{m}^{2}$ in levels - thousand $\mathrm{S} \$$ - rather than in logarithmic scale. The point estimates for the price difference between a freehold unit and a unit with a remaining tenure of 825 to 986 years is $\mathrm{S} \$ 665$ per $\mathrm{m}^{2}$, in the full sample in column (5), or $\mathrm{S} \$ 944$ per $\mathrm{m}^{2}$, dropping original 99-year leaseholds in column (6), with respective s.e. of $\mathrm{S} \$ 284$ and $\mathbf{S} \$ 299$. (Standard errors are two-way clustered by building and purchase year.) As a proportion of the mean purchase price for a freehold in the sample, of $\mathrm{S} \$ 14,100$ per $\mathrm{m}^{2}$, the estimated price differences are $4.7 \%$ and $6.7 \%$, which are comparable to (if somewhat higher than) the values reported in columns (1) and (2) of Table A.1.

Taking the specification in Table 2, column (3) as the baseline, Table A.2 reports robustness with regard to sample composition. In columns (1) and (2), we restrict the sample to units purchased (of any tenure type), respectively: (1) within $0.5 \mathrm{~km}$ of a development project for which we observe transactions of 999-leasehold properties; and (2) in three-digit zip codes that saw transactions of 999-leasehold properties and at least one other tenure type (freeholds or 99-year leaseholds). Both subsamples are variants of the subsamples considered in columns (5) and (6) of Table 2. The robustness of estimates, namely -0.057 (s.e. 0.019) and -0.053 (s.e. 0.015) log points on 825-986year leaseholds, attests to the appropriateness of our hedonic controls. In column (3), we drop 
purchases of units on a building's top floor, which tend to be penthouses, and first floor, which may be next door to common areas. Table A.2, columns (4) and (5) drop purchases of units for which, respectively: (4) construction had not been completed by the end of our sample period, and (5) purchase prices (in thousand $\mathrm{S} \$$ ) are in the bottom or top $1 \%$ of the distribution of prices (for the given tenure type). ${ }^{16}$ Again, estimates are robust to sample composition.

Finally, taking the specification in Table 2, column (3) as the baseline, Table A.3 ("finer controls") reports robustness with regard to the following variants in the set of controls: (column 1) replacing (log) unit size by a full set of unit size dummies in bins of size $10 \mathrm{~m}^{2}$; (2) replacing (log) floor number by a series of individual floor dummies; (3) adding interactions between the larger land parcel dummy, as classified by URA, and the three-digit zip code fixed effects; (4) replacing year fixed effects and quarter fixed effects with year-by-quarter fixed effects; (5) replacing quarter-ofyear fixed effects by month-of-year fixed effects; (6) adding indicators for shared amenities, namely whether the condominium's development offers a swimming pool, gym, or tennis court, for the subsample for which these characteristics are available.

Baseline estimates are very robust. In particular, with finer controls in Table A.3 columns (3) and (4) - geography-by-land parcel size, and year-by-month - the estimated price discount on original 999-year leaseholds relative to freehold grows slightly in magnitude to 0.060 and $0.044 \log$ points, respectively.

\subsection{Structural analysis of discounting in the very long run}

In what follows, we first provide estimates of equation (3), in which disturbances are specified to be additively separable and the dependent variable is the property's transaction price. Recall that if we further specify the flow utility from housing services to be linear in parameters, during optimization we can concentrate out the utility parameters and market fixed effects, $\theta$ and $\xi$, allowing the nonlinear search to take place over only the parameters of the discount rate schedule, $\gamma$. We start exploring this specification- "add.sep. \& lin.util." - with discount rates that are constant over time; we then implement the "add.sep. \& lin.util." specification with alternative parametric structures for $r(t ; \gamma)$, namely exponential, semi-log and hyperbolic.

We find that all three estimated functional forms yield declining discount rates (DDR). However,

\footnotetext{
${ }^{16}$ Table 1 reports that purchase prices in the sample range from $\mathrm{S} \$ 0.3$ to 43.4 million. We manually checked the latter price and, while accurate, it is exceptional in the data. The 1st and 99th percentiles are $\mathrm{S} \$ 0.5$ and 6.4 million.
} 
for short-run (year-1) discount rates of $4 \%$ to $5 \%$ p.a., the exponential form is able to capture a significant price discount for the 825 to 986 -year leaseholds relative to freeholds, as documented by the descriptive dummy-variable regressions of Table 2 . While also declining over time, discount rates under both the semi-log and hyperbolic forms are still too high in the very long run for material differences in the prices of 825 to 986 -year leaseholds and freeholds to be estimated.

Finally, we implement the loglinear estimating equation (2) — "log.lin." Here, the dependent variable is the logarithm of the property's transaction price, and the nonlinear search must take place over the entire space of parameters, $\gamma, \theta$ and $\xi$, i.e., about 220 parameters compared to one or two. While the optimization routine takes longer to converge, we obtain similar discount rate schedules under this specification variant.

\subsubsection{Constant discount rates}

We estimate "add.sep. \& lin.util." equation (3), constraining $\phi\left(T_{i} ; \mathbf{r}\right)$ with $r_{t}=r=\gamma$ (one parameter). The dependent variable is the transaction price per square meter of floor area. In the utility specification, $u\left(X_{i} ; \theta\right)=X_{i} \theta, X_{i}$ includes a quadratic in the unit's size, a quadratic in the unit's floor level, and a quadratic in the development project size, among all other property characteristics that we controlled for in the descriptive regressions of Table 2, including "purchase to completion" year bins and three-digit zip code fixed effects that account for unobserved heterogeneity. ${ }^{17}$

Results for this restrictive rate schedule are reported in Table 3. Using the full sample of properties, we precisely estimate a (constant) discount rate of $2.2 \%$ p.a.-column (1). We estimate a somewhat lower rate of $1.7 \%$ p.a. (resp., $1.8 \%$ p.a.) when we restrict the sample to units sold in only those three-digit zip codes for which we observe sales of both 999-year leaseholds and freeholds (resp., all three tenure types) - subsample composition in columns (2) and (3) is as reported in Table 1. Intuitively, as it is restricted to not vary over time, the discount rate estimated in column (1), and to a lesser extent in columns (3) and (4), is dominated by the original 99-year properties, with shorter maturities, relative to assets with longer maturities. This forms the basis of the conclusions reported by GMS.

Importantly, when we drop the original 99-year leases from the estimation sample, in column (2), we obtain a significantly lower discount rate, of $0.3 \%$ p.a.. This subsample consists only of

\footnotetext{
${ }^{17}$ Results would be very similar had we taken the total transaction price of the unit as the dependent variable (rather than the price per $\mathrm{m}^{2}$ ), or had we controlled for unit size, floor number and development project size in logarithms (rather than quadratics of these variables). These robustness tests parallel those in the descriptive analysis above.
} 
original 999-year leases and freeholds, and the estimate is now driven by the detectable difference in value between assets with utility flows about 900 years into the future and assets with flows in perpetuity: households still attach a premium to "forever" relative to assets with an already very long life of nine centuries. The model rationalizes this difference in value today, corresponding to payoff streams nine centuries away, through a low, yet positive and precisely estimated, discount rate.

The discount rate differences that we estimate for the subsample that excludes assets with shorter maturities compared to the samples that include them-column (2) compared to columns (1), (3) and (4) - is indicative of declining discount rates over time.

A regression diagnostic that we report in Table 3 (and subsequent tables) is the model-predicted average price discount, relative to freeholds, of units with remaining tenure of 825 to 986 years, and, separately, of 87 to 99 years. For example, the estimated model reported in column (1), with a constant discount rate estimated at $2.2 \%$ p.a., predicts a $0.0 \%$ price discount, on average, for 825-986 year leases; to illustrate, this is computed as $\hat{\phi}_{i}$ averaged over all 825-986 year leases in the estimation sample divided by $\hat{\phi}_{i}$ averaged over all freeholds in the sample, with the quotient subtracted from the number $1 .^{18}$ In contrast, column (2) estimates, with $\hat{r}=0.003$ estimated on the subsample that excludes maturities shorter than one century, predicts a positive 825-986 year leasehold price discount, averaging $12 \%$, relative to freeholds. While positive, this discount is higher than what is suggested by the descriptive regressions, of about $5 \%$, suggesting that the constant rate schedule may have trouble accommodating the data.

Before moving to parametric estimates, we further illustrate the empirical finding of declining discount rates by using the full sample and specifying the discount rate to be a step function of time, with a "known" jump at $t=800$, to exploit the very long term maturities with horizons of at least 825 years. In Table 3 , column (5), we constrain $\phi\left(T_{i} ; \mathbf{r}\right)$ as follows:

$$
r_{t}=r(t ; \gamma)=\left\{\begin{array}{c}
\gamma_{1} \text { for } 1<t<800 \\
\gamma_{2} \text { for } t \geq 800
\end{array}\right.
$$

We obtain $\hat{\gamma}_{1} \simeq 0.0264$ (s.e. 0.0030 ) and $\hat{\gamma}_{2} \simeq 0.0000$ (s.e. 0.0000). (Standard errors are clustered by building.) Allowing the rate schedule to jump at a given point in time is arbitrary, but it serves to show that, with added flexibility, the model estimated from the full sample is able to predict a

\footnotetext{
${ }^{18}$ Column (1), with $\hat{r} \simeq 0.0220$, predicts $87-99$ year leasehold price discounts averaging $13 \%$ relative to freeholds.
} 
positive price discount, of about $6 \%$, for $825-986$ year leases relative to freeholds.

\subsubsection{Parametric estimates}

Rather than constrain discount rates to be constant over time, or an arbitrary step function of time, we implement "add.sep. \& lin.util." equation (3) modeling $\phi\left(T_{i} ; \mathbf{r}\right)$ such that the discount rate can vary smoothly over time. Specify the discount rate as an exponential function of time (equivalently, the logarithm of the discount rate is a linear function of time):

$$
r_{t}=r(t ; \gamma)=\left\{\begin{array}{c}
\max \left(\gamma_{1} \exp \left(\gamma_{2}(t-1)\right), \gamma_{3}\right) \text { for } 1<t \leq 10^{6} \\
\max \left(\gamma_{1} \exp \left(\gamma_{2}\left(10^{6}-1\right)\right), \gamma_{3}\right) \text { for } t>10^{6}
\end{array} \quad\left(\text { exponential } r_{t}\right)\right.
$$

Parameter $\gamma_{1}>0$ corresponds to the discount rate in period 1, i.e., $r_{1}$. In what follows, we either fix the year-1 discount rate $\gamma_{1}$ (and report results for different values of $\gamma_{1}$ ), or we estimate $\gamma_{1}$ along with parameter $\gamma_{2}$. Parameter $\gamma_{2} \gtrless 0$ defines the slope of the rate schedule, i.e., declining (DDR) if negative, rising if positive, or flat as in the constant case above. $\gamma_{2}$ is the key parameter of interest. Parameter $\gamma_{3}>0$ provides a lower bound to the discount rate. Throughout the analysis using the exponential and alternative functional forms for the rate schedule, we fix this floor. Specifically, we impose the regularity condition that discount rates are bounded from below at $\gamma_{3}=0.01 \%$ p.a., and provide some sensitivity analysis around this normalization. ${ }^{19}$ Finally, to make estimation computationally tractable, we impose a flat rate schedule beyond year 1,000,000, restricting $r_{t}$ for $t>10^{6}$ to be equal to the estimated discount rate for year 1,000,000.

In an alternative specification for the rate schedule, we restrict $\phi\left(T_{i} ; \mathbf{r}\right)$ such that the discount rate is a logarithmic function of time:

$$
r_{t}=r(t ; \gamma)=\left\{\begin{array}{c}
\max \left(\gamma_{1}+\gamma_{2} \log t, \gamma_{3}\right) \text { for } 1<t \leq 10^{6} \\
\max \left(\gamma_{1}+\gamma_{2} \log 10^{6}, \gamma_{3}\right) \text { for } t>10^{6}
\end{array} \quad \text { (semi-log. } r_{t}\right)
$$

Under this functional form, the discount rate is linear in the logarithm of time. Again, the curvature coefficient $\gamma_{2}$ is the key parameter of interest. A negative $\gamma_{2}$ implies declining discount rates, a zero value for this parameter implies a constant discount rate.

A third functional form that we estimate specifies the discount rate to be a hyperbolic function

\footnotetext{
${ }^{19}$ As the discount rate approaches 0 , the value of an infinite utility stream increases arbitrarily.
} 
of time (equivalently, the logarithm of the discount rate is a linear function of the logarithm of time):

$$
r_{t}=r(t ; \gamma)=\left\{\begin{array}{c}
\max \left(\gamma_{1} t^{\gamma_{2}}, \gamma_{3}\right) \text { for } 1<t \leq 10^{6} \\
\max \left(\gamma_{1}\left(10^{6}\right)^{\gamma_{2}}, \gamma_{3}\right) \text { for } t>10^{6}
\end{array} \quad \text { (hyperbolic } r_{t}\right)
$$

As with the other structures, slope parameter $\gamma_{2}$ is the key one of interest, whereas $\gamma_{1}$ is the period- 1 discount rate and $\gamma_{3}$ bounds the discount rate from below.

Table 4 reports results using the three alternative functional forms for the rate schedule. Again, the dependent variable is the transaction price per square meter of floor area and we use the full sample of properties to trace out the rate schedule over the course of one century (original 99year leases) and beyond (original 999-year leases). In columns (1) to (3), exponential, semi-log and hyperbolic, respectively, we fix the year- 1 discount rate at $4 \%$ p.a.. ${ }^{20}$ In all cases, we obtain discount rates that decline over time. Estimates are very precise. Having fixed $\gamma_{1}=0.04$, the exponential form is able to produce discount rates that fall below $0.5 \%$ p.a. by year 500 . Figure 3 , panels (a) and (b), with the time axis in linear and log scales respectively, plot the three different estimated rate schedules. Compared to the exponential form, the semi-log and hyperbolic forms yield schedules that level off at substantially higher discount rates.

As a result of the substantially lower discount rates starting year 300 compared to the other schedules, the fitted exponential predicts an average 5.9\% transaction price discount for 825-986 year leases relative to comparable freehold properties; see $1-\left(\right.$ mean $\left.\hat{\phi}_{i} 825-986\right) /\left(\right.$ mean $\hat{\phi}_{i}$ freehold $)$ in Table 4. This statistic, for $\gamma_{1}$ fixed at 0.04 , is $0.0 \%$ under the fitted semi-log and hyperbolic forms, indicating that these specifications are unable to account for the freehold premium over original 999-year leases that we observe empirically (Table 2).

The differential discounting of benefits over time across the schedules, and for $\gamma_{1}=0.04$, is also seen in Figure 3, panels (c) and (d), again with the time axis in linear and log scales respectively. We plot the value today of adding an extra year of unitary (\$1) utility, expressed as a proportion of the value of 1,000,000 years of unitary utility flows. For example, as seen in panel (d), an asset paying $\$ 1$ each year from year 1 to year 10 is worth about $20 \%$ of the value of an asset paying $\$ 1$ each year from year 1 to year 1,000,000. Importantly, adding extra years of unitary utility beyond year 300 has no impact on price today according to the fitted semi-log and hyperbolic curvatures

\footnotetext{
${ }^{20}$ In simulations of estimated time-series models of US government bond yields, Newell and Pizer (2003), Groom et al. (2007), and Freeman et al. (2015) fix the starting rate at $4 \%$ p.a., i.e., the pattern of decline is estimated, but not the starting point. We compare our estimated discount rate schedule to this literature in the final section.
} 
(the cumulative value is already essentially 1), whereas incremental utility around year 1000 still has a bearing on price today in the fitted exponential form. For perspective, the discount rate in year 1000 is estimated at $0.04 \%, 1.14 \%$ and $1.53 \%$ p.a. under the exponential, semi-log and hyperbolic forms, respectively, of Table 4, columns (1) to (3).

In Table 4, columns (4) and (5), we estimate the initial rate $\gamma_{1}$ along with the slope parameter $\gamma_{2}$ for the exponential and semi-log forms. These parametrically estimated rate schedules are shown in Figure 4, with the time axis in log scale. This figure summarizes our preferred result, employing an exponential form and the now estimated year-1 discount rate coming in close to $4 \%$ p.a., namely $\hat{\gamma}_{1}=0.039$, and $\hat{\gamma}_{2}$ similar to that reported in column (1). The fitted year-1 discount rate in the case of the semi-log is higher, at $\hat{\gamma}_{1}=0.076$, i.e., close to $8 \%$ p.a.. Estimation under the semi-log form is now able to accommodate observed variation in value many centuries into the futurewith lower very long run discount rates. Estimated discount rates beyond year 50 are remarkably similar for the exponential and the semi-log forms; besides Figure 4, this can also be seen in the model-predicted average price discounts for the 825-986 year maturities relative to perpetuities, reported at the bottom of Table 4 . For example, with $\hat{\gamma}_{1}$ unconstrained and estimated at a high $7.6 \%$ p.a., along with a steep slope of - 0.026 - compared this to -0.010 in column (2) - the semi-log form is now able to account for a 5.8\% discount of 825-986 year leaseholds relative to freeholds.

Tables 5 and 6 report estimates of the slope parameter, $\gamma_{2}$, under each of the three functional forms, from left to right, as we vary, from top to bottom: either the year-1 discount rate, $\gamma_{1}$ (Table 5 ), or the lower bound to the discount rate, $\gamma_{3}$ (Table 6 ). The top of each table reproduces estimates from Table 4 , for $\gamma_{1}=4 \%$ and $\gamma_{3}=0.01 \%$, and beneath these sets of estimates we show estimates with $\gamma_{1}$ alternatively fixed at $5 \%$ p.a., $6 \%$ p.a. or $3 \%$ p.a. in Table 5 , and $\gamma_{3}$ alternatively fixed at $0.1 \%$ p.a. or $0.001 \%$ p.a. in Table 6 .

The sensitivity analysis of Table 5 can be visualized in Figure 5. Panels (a) to (c) plot the estimated discount rate schedule for each year-1 rate (within panel) and each functional form (across panels). As the short-run discount rate decreases, the slope of the rate schedule flattens to compensate. Under an exponential form in panel (a), there is little variation over the first decade (or even five decades); beginning year 700, discount rates—already below $0.5 \%$ p.a.-again display little variation over time. In contrast, rates under a hyperbolic form decline most sharply in the first decade, and remain above $1 \%$ p.a. one millennium into the future, a feature which makes this functional form less appealing when it comes to fitting observed purchase prices. Rates under 
a semi-log form display a pattern that is somewhat in between those for the exponential and the hyperbolic forms. Among the 12 restricted models estimated in Table 5, the exponential form with year-1 rate fixed at $4 \%$ p.a. exhibits the lower RSS (higher $\mathrm{R}^{2}$ ).

Similarly, Figure 6 summarizes the sensitivity with regard to the lower bound analysis reported in Table 6. We plot the fitted exponentials only since estimates for the other functional forms are not sensitive to varying $\gamma_{3}$ in this range. Even for the exponential, the differences are not large, and the specification with $\gamma_{3}$ fixed at $0.01 \%$ p.a. exhibits the lower RSS (higher $\mathrm{R}^{2}$ ) in Table 6 .

Finally, Table 7 reports estimates as we vary the composition of the sample, from left to right, for the different parametric forms, from top to bottom. We again fix $\gamma_{1}$ and $\gamma_{3}$ at $4 \%$ and $0.01 \%$ p.a., respectively. The 12 fitted rate schedules are plotted in Figure 7. In panel (a), the exponential function's estimated slope $\hat{\gamma}_{2}$ is quite robust to sample composition. Compared to the exponential, we find that $\hat{\gamma}_{2}$ is less robust as we fit the semi-log and hyperbolic forms to varying subsamples, in panels (b) and (c), respectively. On entirely dropping the shorter maturities, i.e., properties with 56-99 years of remaining tenure, we are also able to estimate discount rates on the order of $0.5 \%$ p.a. several centuries into the future with the semi-log and hyperbolic forms. Similarly, when conditioning on geographic markets in which both original 999-year leaseholds and freeholds, or all three tenure types, we are limiting the sample frequency of shorter maturities relative to the longer maturities and the perpetuities. Thus, the estimation algorithm places less weight on the sum of squared errors contributed by the original 99-year leaseholds that remain in the sample, and more weight on the differences between observed and model-predicted prices on the longer-lived assets.

Nonlinear search over the entire space of parameters, $\gamma, \theta$ and $\xi$. We now estimate "log.lin." equation (2). The flow-utility parameters and the property-market shocks can no longer be concentrated out, and must be included along with the rate schedule parameters in the nonlinear search, totaling 227 parameters when estimating off the full sample. The dependent variable is now the logarithm of the property unit's transaction price per square meter of floor area. Given our earlier results, we focus on a smoothly varying exponential rate schedule, restricting $\phi\left(T_{i} ; \mathbf{r}\right)$ accordingly, and fix $\gamma_{1}$ and $\gamma_{3}$ at $4 \%$ and $0.01 \%$ p.a., respectively.

Table 8 reports results. As we vary the composition of the sample, fitted slopes are similar, if slightly less steep, compared to those reported earlier, under an alternative assumption on how unobservables enter the structural model. For example, for the full sample in column (1), we estimate a slope of -0.0044 versus -0.0046 in Table 7 , top panel. This slope implies that $825-986$ 
maturities trade at a $4.3 \%$ discount relative to perpetuities, compared to $5.9 \%$ estimated through the lens of the earlier structural model.

\section{Conclusion and policy implications}

We summarize our findings and briefly discuss their relevance, in particular, to policy on climate change. We have provided compelling evidence that, in Singapore's fairly homogeneous privatehousing market, new apartments on historical multi-century leases trade at a non-zero discount relative to property owned in perpetuity. Descriptive regressions suggest that the freehold price premium over otherwise comparable 825 to 986 -year leaseholds is about 4 to $6 \%$. Since the price difference for such long maturities is bound to be small, the market's homogeneity buys us precision. We consider an empirical model in which asset value is decomposed into the flow utility of housing services, which shifts with property characteristics such as detailed geographic location, and a second factor that shifts with asset tenure and the certainty-equivalent discount rate schedule. We allow shocks, both market level (macroeconomic) and idiosyncratic, to account for differences between model-predicted value and observed price.

On restricting the rate schedule to be flat over time, a discount rate estimated at about $0.3 \%$ p.a. can explain observed price differences between perpetuities and the very long run maturities. If instead we allow the rate schedule to vary smoothly over time through some parametric form that exploits the supply of multi-decade leases in addition to the multi-century ones, discount rates that decline over time and are of the order of $0.5 \%$ p.a. by year $400-500$ are estimated to accommodate the observed price differences. The finding that households, making important purchase decisions in a real-world setting, do not entirely discount benefits that accrue many centuries from today is new to a sparse empirical literature on discounting.

Figure 8, panel (a) compares our preferred estimated discount rate schedule to schedules the UK and France currently use to guide public policy (HM Treasury, 2003; Lebègue, 2005). To emphasize, the plotted discount rate, $r_{t}$, discounts benefits from year $t+1$ back to year $t$, i.e., the forward rate (not the "effective term structure," the rate that would discount benefits from year $t$ back to year 0). Interestingly, the discount rates we estimate track the UK schedule until the UK schedule levels off beyond year 300 at $1 \%$ p.a., while the schedule we estimate continues to decline through $0.5 \%$ p.a. over subsequent centuries. 
Figure 8, panel (b) compares our preferred estimated schedule against declining discount rates simulated by Newell and Pizer (2003) and Groom et al. (2007), based on fitting alternative (reducedform) times-series models to historical interest rates for long-term US government bonds. The declining discount rate (DDR) schedules proposed by studies in this empirical "Expected Net Present Value" literature follows from the serial correlation in government bond yield uncertainty (Weitzman, 1998; Arrow et al., 2014). The DDR schedule we estimate from Singapore residential property prices is intermediate to Newell and Pizer's "random walk" model and the subsequent studies that used more flexible econometric models, e.g., Groom et al.'s "state space" model. ${ }^{21}$

Writing in "policy forum" for Science, Arrow et al. (2013) compare a constant 4\% p.a. to the DDR schedules in Newell and Pizer (2003), Groom et al. (2007), and Freeman et al. (2015). Arrow and the 12 other notable scholars state: "In these studies, estimates of the social cost of carbon are increased by as much as two- to threefold by using a DDR, compared with using a constant discount rate of $4 \%$, the historic mean return on U.S. Treasury bonds" (p.350). As pointed out by Giglio et al. (2015b), the risk profile of real estate assets may differ from that of climate-change abating assets. Yet, unknown risk differences aside, Figure 8 suggests that the DDR we directly estimate from households' observed choices in a real-world market for new property would similarly raise the social cost of carbon substantially.

\footnotetext{
${ }^{21}$ As their preferred specification, Newell and Pizer (2003) fit an $\operatorname{AR}(p)$ model to the logarithm of annual US interest rates (partly adjusted for variation in the CPI), with the sum of autoregressive parameters restricted to 1 , i.e., an autoregressive random walk model. They then use the estimated model to simulate thousands of interest rate paths. Following Weitzman (1998), the certainty-equivalent forward rate, $r_{t}$, is then given by $\left(1+r_{t}\right)^{-1}=$ $E\left[e^{-r_{1}} e^{-r_{2}} \ldots e^{-r_{t}} e^{-r_{t+1}}\right] / E\left[e^{-r_{1}} e^{-r_{2}} \ldots e^{-r_{t}}\right]$, where the expectation is taken over the simulated paths. Among other models, Groom et al. (2007) allow for time-dependent parameters by modeling an AR(1) process with an $\operatorname{AR}(p)$ coefficient. Subsequently, Freeman et al. (2015) use a more complete inflation history to model the process driving the CPI separately from that generating the nominal interest rate.
} 
Table 1: Descriptive statistics for new condominium purchases.

Panel A: Sales volume over time and by lease type

Year unit was sold:

Total

$\begin{array}{lll}1995-1999 \quad 2000-2004 & 2005-2009 \quad 2010-2015\end{array}$ (\# of units)

Tenure Remaining:

Freehold

876 to 986 years

825 to 875 years

91 to 99 years

87 to 90 years

56 to 63 years

Total (\# of units)

\begin{tabular}{ccccc}
\hline \multicolumn{5}{c}{ Full sample } \\
\hline 13,599 & 10,989 & 27,206 & 21,040 & 72,834 \\
3,093 & 825 & 353 & 0 & 4,271 \\
657 & 330 & 2,524 & 1,372 & 4,883 \\
18,932 & 16,207 & 15,630 & 45,336 & 96,105 \\
0 & 44 & 9 & 835 & 888 \\
0 & 0 & 14 & 223 & 237 \\
36,281 & 28,395 & 45,736 & 68,806 & 179,218
\end{tabular}

Tenure Remaining:

Freehold

876 to 986 years

825 to 875 years

91 to 99 years

87 to 90 years

56 to 63 years

Total (\# of units)

Tenure Remaining:

Freehold

876 to 986 years

825 to 875 years

28,395

45,736

68,806

179,218

91 to 99 years

87 to 90 years

56 to 63 years

Restrict to 3-digit zip codes with both $825-986$ and freehold sales

$\begin{array}{ccccc}5,384 & 2,583 & 6,775 & 4,417 & 19,159 \\ 1,931 & 763 & 347 & 0 & 3,041 \\ 388 & 272 & 2,147 & 1,242 & 4,049 \\ 1,125 & 935 & 536 & 2,192 & 4,788 \\ 0 & 33 & 2 & 0 & 35 \\ 0 & 0 & 0 & 0 & 0 \\ 8,828 & 4,586 & 9,807 & 7,851 & 31,072\end{array}$

Total (\# of units)

Restrict to 3-digit zip codes with sales of all three lease types

$\begin{array}{ccccc}2,567 & 1,567 & 5,866 & 2,831 & 12,831 \\ 1,092 & 612 & 246 & 0 & 1,950 \\ 388 & 121 & 1,964 & 674 & 3,147 \\ 1,125 & 935 & 536 & 2,192 & 4,788 \\ 0 & 33 & 2 & 0 & 35 \\ 0 & 0 & 0 & 0 & 0 \\ 5,172 & 3,268 & 8,614 & 5,697 & 22,751\end{array}$

Panel B: Other transaction statistics

Price per $\mathrm{m}^{2}(\mathrm{~S} \$)$

Unit size $\left(\mathrm{m}^{2}\right)$

Transaction price $(\mathrm{S} \$)$

Floor

First floor of building ( $1=$ yes)

Top floor of building ( $1=$ yes)

Project size (number of units)

Larger land parcel (1=yes)

Sold $\geq 1$ year after complete

$\frac{\mathrm{N}}{179,218}$

Mean

Std. Dev.

Minimum

Maximum

Sold before completion

179,218

179,218

179,218

179,218

179,218

179,218

179,218

179,218

179,218

$\begin{array}{ccc}12,374 & 5,530 & 2,67 \\ 107.999 & 47.440 & \\ 1,336,314 & 1,181,158 & 308,2 \\ 8.999 & 7.590 & \\ 0.059 & 0.236 & \\ 0.086 & 0.280 & \\ 367.563 & 266.034 & \\ 0.703 & 0.457 & \\ 0.035 & 0.185 & \\ 0.869 & 0.337 & \end{array}$

2,670
24
308,248
1
0
0
1
0
0
0

78,068

$4 \quad 1,186$

, $248,396,372$

$1 \quad 70$

0 1

$0 \quad 1$

$1 \quad 1,371$

Notes: See text for data sources. Prices in January $2014 \mathrm{~S} \$$. Project size is the number of units transacted within the development (for which caveats were lodged with the Singapore Land Authority- see Appendix A.1). Larger land parcel is a project-specific dummy variable according to URA's classification. 
Table 2: (Descriptive) Value in the very long run: Transaction price per $\mathrm{m}^{2}$, in log.

\begin{tabular}{|c|c|c|c|c|c|c|}
\hline \multirow[t]{2}{*}{ Sample: } & \multicolumn{3}{|c|}{ Full sample } & \multirow{2}{*}{$\begin{array}{c}\text { Drop } \\
56-99 \\
\text { leases } \\
(4)\end{array}$} & \multirow{2}{*}{$\begin{array}{c}\text { Only zips } \\
\text { w/ 825-986 } \\
\text { \& freehold } \\
(5)\end{array}$} & \multirow{2}{*}{$\begin{array}{c}\text { Only zips } \\
\text { with all } \\
\text { lease types } \\
(6)\end{array}$} \\
\hline & $(1)$ & $(2)$ & $(3)$ & & & \\
\hline 825 to 986 years $(1=$ yes $)$ & $\begin{array}{c}-0.095^{* *} \\
(0.041)\end{array}$ & $\begin{array}{c}-0.042^{* * *} \\
(0.016)\end{array}$ & $\begin{array}{c}-0.038^{* *} \\
(0.016)\end{array}$ & $\begin{array}{c}-0.060^{* * *} \\
(0.016)\end{array}$ & $\begin{array}{c}-0.050^{* * *} \\
(0.016)\end{array}$ & $\begin{array}{c}-0.061^{* * *} \\
(0.020)\end{array}$ \\
\hline 87 to 99 years $(1=$ yes $)$ & $\begin{array}{c}-0.305^{* * *} \\
(0.021)\end{array}$ & $\begin{array}{c}-0.154^{* * *} \\
(0.011)\end{array}$ & $\begin{array}{c}-0.155^{* * *} \\
(0.011)\end{array}$ & & $\begin{array}{c}-0.199 * * * \\
(0.026)\end{array}$ & $\begin{array}{c}-0.191^{* * * *} \\
(0.025)\end{array}$ \\
\hline 56 to 63 years $(1=$ yes $)$ & $\begin{array}{c}-0.353^{* * *} \\
(0.043)\end{array}$ & $\begin{array}{c}-0.351^{* * *} \\
(0.038)\end{array}$ & $\begin{array}{c}-0.343^{* * *} \\
(0.037)\end{array}$ & & & \\
\hline Unit size $\left(\log , \mathrm{m}^{2}\right)$ & $\begin{array}{c}-0.062^{* *} \\
(0.026)\end{array}$ & $\begin{array}{c}-0.115^{* * *} \\
(0.022)\end{array}$ & $\begin{array}{c}-0.096^{* * *} \\
(0.024)\end{array}$ & $\begin{array}{c}-0.074^{* * *} \\
(0.025)\end{array}$ & $\begin{array}{l}-0.048 \\
(0.035)\end{array}$ & $\begin{array}{l}-0.023 \\
(0.040)\end{array}$ \\
\hline Floor $(\log )$ & $\begin{array}{c}0.121^{* * *} \\
(0.012)\end{array}$ & $\begin{array}{c}0.059^{* * *} \\
(0.005)\end{array}$ & $\begin{array}{c}0.069^{* * *} \\
(0.006)\end{array}$ & $\begin{array}{c}0.078^{* * *} \\
(0.008)\end{array}$ & $\begin{array}{c}0.054^{* * *} \\
(0.006)\end{array}$ & $\begin{array}{c}0.054^{* * *} \\
(0.007)\end{array}$ \\
\hline First floor of building ( $1=$ yes $)$ & & & $\begin{array}{l}0.018^{*} \\
(0.010)\end{array}$ & $\begin{array}{c}0.032^{* * *} \\
(0.012)\end{array}$ & $\begin{array}{c}0.004 \\
(0.012)\end{array}$ & $\begin{array}{c}0.010 \\
(0.014)\end{array}$ \\
\hline Top floor of building ( $1=$ yes $)$ & & & $\begin{array}{c}-0.088^{* * *} \\
(0.011)\end{array}$ & $\begin{array}{c}-0.107^{* * *} \\
(0.015)\end{array}$ & $\begin{array}{c}-0.081^{* * *} \\
(0.015)\end{array}$ & $\begin{array}{c}-0.067^{* * *} \\
(0.014)\end{array}$ \\
\hline Project size (log) & & & $\begin{array}{l}-0.005 \\
(0.007)\end{array}$ & $\begin{array}{l}-0.006 \\
(0.009)\end{array}$ & $\begin{array}{l}-0.016 \\
(0.014)\end{array}$ & $\begin{array}{l}-0.014 \\
(0.016)\end{array}$ \\
\hline Purchase-completion year bins & No & No & Yes & Yes & Yes & Yes \\
\hline 3-digit zip code fixed effects & No & Yes & Yes & Yes & Yes & Yes \\
\hline Larger land parcel fixed effect & No & Yes & Yes & Yes & Yes & Yes \\
\hline Purchase year fixed effects & Yes & Yes & Yes & Yes & Yes & Yes \\
\hline Quarter-of-year fixed effects & Yes & Yes & Yes & Yes & Yes & Yes \\
\hline $\mathrm{R}^{2}$ & 0.484 & 0.845 & 0.851 & 0.828 & 0.853 & 0.858 \\
\hline Observations & 179,218 & 179,218 & 179,218 & 81,988 & 31,072 & 22,751 \\
\hline Number of regressors & 29 & 216 & 225 & 180 & 62 & 50 \\
\hline Dependent variable mean & 9.345 & 9.345 & 9.345 & 9.462 & 9.412 & 9.426 \\
\hline
\end{tabular}

Notes: ${ }^{* * *} \mathrm{p}<0.01,{ }^{* *} \mathrm{p}<0.05,^{*} \mathrm{p}<0.1$. The dependent variable is the logarithm of the property's transaction price divided by the size of the unit (in January $2014 \mathrm{~S} \$$ per $\mathrm{m}^{2}$ ). Project size is the number of units transacted within the development (for which caveats were lodged with the Singapore Land Authority-see Appendix A.1). Purchase-completion year bins are a full set of dummies that indicate the time difference (negative or positive) between transaction and building completion. Larger land parcel is a project-specific dummy variable according to URA's classification. OLS regressions. Standard errors, in parentheses, are clustered by building and purchase year. Columns (1) to (3) use the full sample (all new condominium purchases from 1995 to 2015). Column (4) restricts the sample to purchases of 825 to 986-year leases or of freeholds. Column (5) (resp., (6)) considers purchases of any lease type but only in 3-digit zip codes with recorded sales of both 825 to 986-year leases and freeholds (resp., of all three lease types). Table 1 lists the composition of samples. In all columns the dummy for freeholds is omitted. 
Table 3: (Structural) Discount rates restricted to be flat over time.

\begin{tabular}{|c|c|c|c|c|c|}
\hline Sample: & $\begin{array}{c}\text { Full } \\
(1)\end{array}$ & $\begin{array}{c}\text { Drop } \\
56-99 \\
\text { leases } \\
(2) \\
\end{array}$ & $\begin{array}{c}\text { Only zips } \\
\text { w/ 825-986 } \\
\& \text { freehold } \\
(3)\end{array}$ & $\begin{array}{c}\text { Only zips } \\
\text { with all } \\
\text { lease types } \\
\text { (4) }\end{array}$ & $\begin{array}{c}\text { Full } \\
(5)\end{array}$ \\
\hline \multicolumn{6}{|l|}{ Rate schedule parameters: } \\
\hline Discount rate (p.a.) & $\begin{array}{c}0.0218 \\
(0.0034)\end{array}$ & $\begin{array}{c}0.0025 \\
(0.0002)\end{array}$ & $\begin{array}{c}0.0173 \\
(0.0051)\end{array}$ & $\begin{array}{c}0.0181 \\
(0.0058)\end{array}$ & \\
\hline Discount rate, up to year 800 (p.a.) & & & & & $\begin{array}{c}0.0264 \\
(0.0030)\end{array}$ \\
\hline Discount rate, from year 800 (p.a.) & & & & & $\begin{array}{c}0.0000 \\
(0.0000)\end{array}$ \\
\hline \multicolumn{6}{|l|}{ Housing-services utility parameters: } \\
\hline Unit size $\left(\mathrm{m}^{2} / 100\right)$ & $\begin{array}{l}-0.0282 \\
(0.0080)\end{array}$ & $\begin{array}{l}-0.0015 \\
(0.0010)\end{array}$ & $\begin{array}{l}-0.0196 \\
(0.0161)\end{array}$ & $\begin{array}{l}-0.0079 \\
(0.0183)\end{array}$ & $\begin{array}{l}-0.0321 \\
(0.0086)\end{array}$ \\
\hline Unit size squared $\left(\mathrm{m}^{4} / 10^{4}\right)$ & $\begin{array}{c}0.0083 \\
(0.0024)\end{array}$ & $\begin{array}{c}0.0006 \\
(0.0003)\end{array}$ & $\begin{array}{c}0.0088 \\
(0.0047)\end{array}$ & $\begin{array}{c}0.0079 \\
(0.0052)\end{array}$ & $\begin{array}{c}0.0094 \\
(0.0024)\end{array}$ \\
\hline Floor $(/ 10)$ & $\begin{array}{c}0.0320 \\
(0.0055)\end{array}$ & $\begin{array}{c}0.0032 \\
(0.0009)\end{array}$ & $\begin{array}{c}0.0246 \\
(0.0082)\end{array}$ & $\begin{array}{c}0.0290 \\
(0.0097)\end{array}$ & $\begin{array}{c}0.0361 \\
(0.0067)\end{array}$ \\
\hline Floor squared $(/ 100)$ & $\begin{array}{l}-0.0005 \\
(0.0019)\end{array}$ & $\begin{array}{c}0.0003 \\
(0.0006)\end{array}$ & $\begin{array}{l}-0.0026 \\
(0.0020)\end{array}$ & $\begin{array}{l}-0.0040 \\
(0.0023)\end{array}$ & $\begin{array}{l}-0.0005 \\
(0.0022)\end{array}$ \\
\hline First floor of building ( $1=$ yes $)$ & $\begin{array}{l}-0.0098 \\
(0.0029)\end{array}$ & $\begin{array}{c}-0.0014 \\
(0.0003)\end{array}$ & $\begin{array}{l}-0.0069 \\
(0.0031)\end{array}$ & $\begin{array}{l}-0.0045 \\
(0.0035)\end{array}$ & $\begin{array}{l}-0.0113 \\
(0.0025)\end{array}$ \\
\hline Top floor of building ( $1=$ yes) & $\begin{array}{l}-0.0309 \\
(0.0045)\end{array}$ & $\begin{array}{l}-0.0041 \\
(0.0005)\end{array}$ & $\begin{array}{l}-0.0232 \\
(0.0067)\end{array}$ & $\begin{array}{l}-0.0233 \\
(0.0072)\end{array}$ & $\begin{array}{c}-0.0352 \\
(0.0044)\end{array}$ \\
\hline Project size $(/ 100)$ & $\begin{array}{l}-0.0018 \\
(0.0037)\end{array}$ & $\begin{array}{c}-0.0009 \\
(0.0009)\end{array}$ & $\begin{array}{l}-0.0046 \\
(0.0036)\end{array}$ & $\begin{array}{l}-0.0049 \\
(0.0043)\end{array}$ & $\begin{array}{l}-0.0018 \\
(0.0040)\end{array}$ \\
\hline Project size squared $\left(/ 10^{4}\right)$ & $\begin{array}{l}-0.0003 \\
(0.0003)\end{array}$ & $\begin{array}{c}0.0000 \\
(0.0001)\end{array}$ & $\begin{array}{c}0.0001 \\
(0.0003)\end{array}$ & $\begin{array}{c}0.0001 \\
(0.0004)\end{array}$ & $\begin{array}{l}-0.0003 \\
(0.0004)\end{array}$ \\
\hline Purchase-completion year bins & Yes & Yes & Yes & Yes & Yes \\
\hline 3-digit zip code fixed effects & Yes & Yes & Yes & Yes & Yes \\
\hline Larger land parcel dummy & Yes & Yes & Yes & Yes & Yes \\
\hline Purchase year fixed effects & Yes & Yes & Yes & Yes & Yes \\
\hline Quarter-of-year fixed effects & Yes & Yes & Yes & Yes & Yes \\
\hline 1-(mean $\left.\hat{\phi}_{i} 825-986\right) /\left(\right.$ mean $\hat{\phi}_{i}$ freeh. $)$ & 0.000 & 0.115 & 0.000 & 0.000 & 0.058 \\
\hline 1-(mean $\left.\hat{\phi}_{i} 87-99\right) /\left(\right.$ mean $\hat{\phi}_{i}$ freeh. $)$ & 0.128 & - & 0.196 & 0.182 & 0.138 \\
\hline $\operatorname{RSS}(/ \mathrm{N})$ & 7.0718 & 9.7034 & 7.9601 & 9.5141 & 7.0572 \\
\hline $\mathrm{R}^{2}$ & 0.7688 & 0.7471 & 0.7697 & 0.7658 & 0.7693 \\
\hline Observations & 179,218 & 81,988 & 31,072 & 22,751 & 179,218 \\
\hline
\end{tabular}

Notes: The estimating equation is based on additively separable errors and housing-service utility that is linear in parameters. The dependent variable is the property's transaction price divided by the size of the unit (in 1000 January $2014 \mathrm{~S} \$$ per $\mathrm{m}^{2}$ ). See the notes to Table 2 for variable definitions. Nonlinear least squares estimates. Standard errors, in parentheses, are clustered by building. Solver Knitro using interior-point algorithm with $r$ constrained between 0 and 0.1 (i.e., $10 \%$ p.a.), but estimates are robust to using unconstrained optimization with a global search algorithm (Matlab's fminsearch). Columns (1) and (5) use the full sample. Column (2) restricts the sample to purchases of 825 to 986 -year leases or of freeholds. Column (3) (resp., (4)) considers purchases of any lease type but only in 3-digit zip codes with both 825 to 986-year lease and freehold types (resp., all three lease types). 
Table 4: (Structural) Discount rates as parametric functions of time.

\begin{tabular}{|c|c|c|c|c|c|}
\hline Functional form: & $\begin{array}{c}\text { Exponential } \\
\text { (1) }\end{array}$ & $\begin{array}{l}\text { Semi-log } \\
(2)\end{array}$ & $\begin{array}{c}\text { Hyperbolic } \\
\text { (3) }\end{array}$ & $\begin{array}{c}\text { Exponential } \\
\text { (4) }\end{array}$ & $\begin{array}{c}\text { Semi-log } \\
(5)\end{array}$ \\
\hline $\begin{array}{l}\text { Rate schedule parameters: } \\
\gamma_{1} \text { (year-1 discount rate, p.a.) }\end{array}$ & Fix at 0.04 & Fix at 0.04 & Fix at 0.04 & $\begin{array}{c}0.0393 \\
(0.0118)\end{array}$ & $\begin{array}{c}0.0763 \\
(0.0204)\end{array}$ \\
\hline$\gamma_{2}$ (slope parameter) & $\begin{array}{l}-0.0046 \\
(0.0003)\end{array}$ & $\begin{array}{l}-0.0095 \\
(0.0016)\end{array}$ & $\begin{array}{l}-0.1396 \\
(0.0308)\end{array}$ & $\begin{array}{l}-0.0045 \\
(0.0014)\end{array}$ & $\begin{array}{c}-0.0264 \\
(0.0083)\end{array}$ \\
\hline \multicolumn{6}{|l|}{ Housing-services utility parameters: } \\
\hline Unit size $\left(\mathrm{m}^{2} / 100\right)$ & $\begin{array}{l}-0.0413 \\
(0.0109)\end{array}$ & $\begin{array}{l}-0.0342 \\
(0.0092)\end{array}$ & $\begin{array}{l}-0.0332 \\
(0.0090)\end{array}$ & $\begin{array}{l}-0.0408 \\
(0.0152)\end{array}$ & $\begin{array}{c}-0.0511 \\
(0.0192)\end{array}$ \\
\hline Unit size squared $\left(\mathrm{m}^{4} / 10^{4}\right)$ & $\begin{array}{c}0.0122 \\
(0.0030)\end{array}$ & $\begin{array}{c}0.0101 \\
(0.0026)\end{array}$ & $\begin{array}{c}0.0098 \\
(0.0026)\end{array}$ & $\begin{array}{c}0.0120 \\
(0.0044)\end{array}$ & $\begin{array}{c}0.0151 \\
(0.0055)\end{array}$ \\
\hline Floor $(/ 10)$ & $\begin{array}{c}0.0466 \\
(0.0074)\end{array}$ & $\begin{array}{c}0.0388 \\
(0.0062)\end{array}$ & $\begin{array}{c}0.0377 \\
(0.0060)\end{array}$ & $\begin{array}{c}0.0460 \\
(0.0124)\end{array}$ & $\begin{array}{c}0.0577 \\
(0.0157)\end{array}$ \\
\hline Floor squared $(/ 100)$ & $\begin{array}{l}-0.0006 \\
(0.0028)\end{array}$ & $\begin{array}{l}-0.0006 \\
(0.0023)\end{array}$ & $\begin{array}{l}-0.0006 \\
(0.0022)\end{array}$ & $\begin{array}{l}-0.0006 \\
(0.0028)\end{array}$ & $\begin{array}{l}-0.0008 \\
(0.0035)\end{array}$ \\
\hline First floor of building ( $1=$ yes $)$ & $\begin{array}{l}-0.0146 \\
(0.0032)\end{array}$ & $\begin{array}{l}-0.0118 \\
(0.0031)\end{array}$ & $\begin{array}{l}-0.0115 \\
(0.0030)\end{array}$ & $\begin{array}{l}-0.0144 \\
(0.0053)\end{array}$ & $\begin{array}{c}-0.0181 \\
(0.0068)\end{array}$ \\
\hline Top floor of building ( $1=$ yes $)$ & $\begin{array}{l}-0.0454 \\
(0.0037)\end{array}$ & $\begin{array}{l}-0.0374 \\
(0.0040)\end{array}$ & $\begin{array}{l}-0.0364 \\
(0.0040)\end{array}$ & $\begin{array}{l}-0.0448 \\
(0.0112)\end{array}$ & $\begin{array}{l}-0.0562 \\
(0.0144)\end{array}$ \\
\hline Project size $(/ 100)$ & $\begin{array}{l}-0.0024 \\
(0.0053)\end{array}$ & $\begin{array}{l}-0.0022 \\
(0.0044)\end{array}$ & $\begin{array}{l}-0.0022 \\
(0.0043)\end{array}$ & $\begin{array}{l}-0.0024 \\
(0.0055)\end{array}$ & $\begin{array}{l}-0.0030 \\
(0.0070)\end{array}$ \\
\hline Project size squared $\left(/ 10^{4}\right)$ & $\begin{array}{l}-0.0004 \\
(0.0004)\end{array}$ & $\begin{array}{l}-0.0003 \\
(0.0004)\end{array}$ & $\begin{array}{l}-0.0003 \\
(0.0003)\end{array}$ & $\begin{array}{l}-0.0004 \\
(0.0004)\end{array}$ & $\begin{array}{l}-0.0005 \\
(0.0005)\end{array}$ \\
\hline Purchase-completion year bins & Yes & Yes & Yes & Yes & Yes \\
\hline 3-digit zip code fixed effects & Yes & Yes & Yes & Yes & Yes \\
\hline Larger land parcel dummy & Yes & Yes & Yes & Yes & Yes \\
\hline Market shocks: & & & & & \\
\hline Purchase year fixed effects & Yes & Yes & Yes & Yes & Yes \\
\hline Quarter-of-year fixed effects & Yes & Yes & Yes & Yes & Yes \\
\hline 1-(mean $\left.\hat{\phi}_{i} 825-986\right) /\left(\right.$ mean $\hat{\phi}_{i}$ freeh. $)$ & 0.059 & 0.000 & 0.000 & 0.057 & 0.058 \\
\hline 1-(mean $\left.\hat{\phi}_{i} 87-99\right) /\left(\right.$ mean $\hat{\phi}_{i}$ freeh. $)$ & 0.138 & 0.130 & 0.130 & 0.139 & 0.139 \\
\hline RSS $(/ N)$ & 7.0581 & 7.0724 & 7.0722 & 7.0581 & 7.0586 \\
\hline $\mathrm{R}^{2}$ & 0.7692 & 0.7688 & 0.7688 & 0.7692 & 0.7692 \\
\hline Observations & 179,218 & 179,218 & 179,218 & 179,218 & 179,218 \\
\hline
\end{tabular}

Notes: The estimating equation is based on additively separable errors and housing-service utility that is linear in parameters. The dependent variable is the property's transaction price divided by the size of the unit (in 1000 January $2014 \mathrm{~S} \$$ per $\mathrm{m}^{2}$ ). See the notes to Table 2 for variable definitions. Nonlinear least squares estimates. Standard errors, in parentheses, are clustered by building. Solver Knitro using interior-point algorithm with $\gamma_{3}$ fixed at 0.0001 (i.e., $0.01 \%$ p.a.). $\gamma_{1}$ is constrained between 0.0001 and 0.1 in column (4), and between 0.01 and 0.1 in column (5). All estimates are robust to using unconstrained optimization with a global search algorithm (Matlab's fminsearch), and are based on the full sample. 
Table 5: Sensitivity analysis: Varying the year-1 discount rate, $\gamma_{1}$.

\begin{tabular}{|c|c|c|c|}
\hline Functional form: & $\begin{array}{c}\text { Exponential } \\
\text { (1) }\end{array}$ & $\begin{array}{l}\text { Semi-log } \\
\quad(2)\end{array}$ & $\begin{array}{c}\text { Hyperbolic } \\
(3)\end{array}$ \\
\hline & \multicolumn{3}{|c|}{$\gamma_{1}$ fixed at $4 \%$ p.a. (year-1 discount rate) } \\
\hline$\gamma_{2}$ (slope parameter) & $\begin{array}{l}-0.0046 \\
(0.0003)\end{array}$ & $\begin{array}{l}-0.0095 \\
(0.0016)\end{array}$ & $\begin{array}{l}-0.1396 \\
(0.0308)\end{array}$ \\
\hline 1-(mean $\left.\hat{\phi}_{i} 825-986\right) /\left(\right.$ mean $\hat{\phi}_{i}$ freehold $)$ & 0.059 & 0.000 & 0.000 \\
\hline 1-(mean $\left.\hat{\phi}_{i} 87-99\right) /\left(\right.$ mean $\hat{\phi}_{i}$ freehold $)$ & 0.138 & 0.130 & 0.130 \\
\hline $\mathrm{RSS}(/ \mathrm{N})$ & 7.0581 & 7.0724 & 7.0722 \\
\hline \multirow[t]{2}{*}{$\mathrm{R}^{2}$} & 0.7692 & 0.7688 & 0.7688 \\
\hline & \multicolumn{3}{|c|}{$\gamma_{1}$ fixed at $5 \%$ p.a. (year- 1 discount rate) } \\
\hline$\gamma_{2}$ (slope parameter) & $\begin{array}{l}-0.0058 \\
(0.0003)\end{array}$ & $\begin{array}{l}-0.0147 \\
(0.0016)\end{array}$ & $\begin{array}{l}-0.1914 \\
(0.0337)\end{array}$ \\
\hline $1-\left(\right.$ mean $\left.\hat{\phi}_{i} 825-986\right) /\left(\right.$ mean $\hat{\phi}_{i}$ freehold $)$ & 0.079 & 0.000 & 0.000 \\
\hline $1-\left(\right.$ mean $\left.\hat{\phi}_{i} 87-99\right) /\left(\right.$ mean $\hat{\phi}_{i}$ freehold $)$ & 0.132 & 0.130 & 0.130 \\
\hline RSS (/N) & 7.0613 & 7.0727 & 7.0724 \\
\hline \multirow[t]{2}{*}{$\mathrm{R}^{2}$} & 0.7691 & 0.7688 & 0.7688 \\
\hline & \multicolumn{3}{|c|}{$\gamma_{1}$ fixed at $6 \%$ p.a. (year-1 discount rate) } \\
\hline$\gamma_{2}$ (slope parameter) & $\begin{array}{l}-0.0070 \\
(0.0003)\end{array}$ & $\begin{array}{l}-0.0196 \\
(0.0002)\end{array}$ & $\begin{array}{l}-0.2339 \\
(0.0295)\end{array}$ \\
\hline 1-(mean $\left.\hat{\phi}_{i} 825-986\right) /\left(\right.$ mean $\hat{\phi}_{i}$ freehold $)$ & 0.090 & 0.023 & 0.000 \\
\hline $1-\left(\right.$ mean $\left.\hat{\phi}_{i} 87-99\right) /\left(\right.$ mean $\hat{\phi}_{i}$ freehold $)$ & 0.129 & 0.145 & 0.130 \\
\hline $\operatorname{RSS}(/ \mathrm{N})$ & 7.0659 & 7.0652 & 7.0726 \\
\hline \multirow[t]{2}{*}{$\mathrm{R}^{2}$} & 0.7690 & 0.7690 & 0.7688 \\
\hline & \multicolumn{3}{|c|}{$\gamma_{1}$ fixed at $3 \%$ p.a. (year-1 discount rate) } \\
\hline$\gamma_{2}$ (slope parameter) & $\begin{array}{l}-0.0031 \\
(0.0005)\end{array}$ & $\begin{array}{l}-0.0043 \\
(0.0017)\end{array}$ & $\begin{array}{l}-0.0731 \\
(0.0416)\end{array}$ \\
\hline $1-\left(\right.$ mean $\left.\hat{\phi}_{i} 825-986\right) /\left(\right.$ mean $\hat{\phi}_{i}$ freehold $)$ & 0.022 & 0.000 & 0.000 \\
\hline $1-\left(\right.$ mean $\left.\hat{\phi}_{i} 87-99\right) /\left(\right.$ mean $\hat{\phi}_{i}$ freehold $)$ & 0.145 & 0.130 & 0.130 \\
\hline $\operatorname{RSS}(/ \mathrm{N})$ & 7.0650 & 7.0720 & 7.0720 \\
\hline $\mathrm{R}^{2}$ & 0.7690 & 0.7688 & 0.7688 \\
\hline Observations & 179,218 & 179,218 & 179,218 \\
\hline
\end{tabular}


Table 6: Sensitivity analysis: Varying the lower bound to the discount rate, $\gamma_{3}$.

\begin{tabular}{|c|c|c|c|}
\hline Functional form: & $\begin{array}{c}\text { Exponential } \\
\text { (1) }\end{array}$ & $\begin{array}{c}\text { Semi-log } \\
(2)\end{array}$ & $\begin{array}{c}\text { Hyperbolic } \\
(3)\end{array}$ \\
\hline & \multicolumn{3}{|c|}{$\gamma_{3}$ fixed at $0.01 \%$ p.a. (lower bound) } \\
\hline$\gamma_{2}$ (slope parameter) & $\begin{array}{l}-0.0046 \\
(0.0003)\end{array}$ & $\begin{array}{l}-0.0095 \\
(0.0016)\end{array}$ & $\begin{array}{l}-0.1396 \\
(0.0308)\end{array}$ \\
\hline $1-\left(\right.$ mean $\left.\hat{\phi}_{i} 825-986\right) /\left(\right.$ mean $\hat{\phi}_{i}$ freehold $)$ & 0.059 & 0.000 & 0.000 \\
\hline 1-(mean $\left.\hat{\phi}_{i} 87-99\right) /\left(\right.$ mean $\hat{\phi}_{i}$ freehold $)$ & 0.138 & 0.130 & 0.130 \\
\hline $\operatorname{RSS}(/ \mathrm{N})$ & 7.0581 & 7.0724 & 7.0722 \\
\hline \multirow[t]{2}{*}{$\mathrm{R}^{2}$} & 0.7692 & 0.7688 & 0.7688 \\
\hline & \multicolumn{3}{|c|}{$\gamma_{3}$ fixed at $0.1 \%$ p.a. (lower bound) } \\
\hline$\gamma_{2}$ (slope parameter) & $\begin{array}{l}-0.0056 \\
(0.0007)\end{array}$ & $\begin{array}{l}-0.0095 \\
(0.0016)\end{array}$ & $\begin{array}{l}-0.1396 \\
(0.0308)\end{array}$ \\
\hline 1-(mean $\left.\hat{\phi}_{i} 825-986\right) /\left(\right.$ mean $\hat{\phi}_{i}$ freehold $)$ & 0.026 & 0.000 & 0.000 \\
\hline 1- $\left(\right.$ mean $\left.\hat{\phi}_{i} 87-99\right) /\left(\right.$ mean $\hat{\phi}_{i}$ freehold $)$ & 0.141 & 0.130 & 0.130 \\
\hline $\operatorname{RSS}(/ \mathrm{N})$ & 7.0625 & 7.0724 & 7.0722 \\
\hline \multirow[t]{2}{*}{$\mathrm{R}^{2}$} & 0.7691 & 0.7688 & 0.7688 \\
\hline & \multicolumn{3}{|c|}{$\gamma_{3}$ fixed at $0.001 \%$ p.a. (lower bound) } \\
\hline$\gamma_{2}$ (slope parameter) & $\begin{array}{l}-0.0037 \\
(0.0002)\end{array}$ & $\begin{array}{l}-0.0095 \\
(0.0016)\end{array}$ & $\begin{array}{l}-0.1396 \\
(0.0308)\end{array}$ \\
\hline $1-\left(\right.$ mean $\left.\hat{\phi}_{i} 825-986\right) /\left(\right.$ mean $\hat{\phi}_{i}$ freehold $)$ & 0.073 & 0.000 & 0.000 \\
\hline 1-(mean $\left.\hat{\phi}_{i} 87-99\right) /\left(\right.$ mean $\hat{\phi}_{i}$ freehold $)$ & 0.133 & 0.130 & 0.130 \\
\hline $\operatorname{RSS}(/ \mathrm{N})$ & 7.0598 & 7.0724 & 7.0722 \\
\hline $\mathrm{R}^{2}$ & 0.7692 & 0.7688 & 0.7688 \\
\hline Observations & 179,218 & 179,218 & 179,218 \\
\hline
\end{tabular}

Notes: The estimating equation is based on additively separable errors and housing-service utility that is linear in parameters. The dependent variable is the property's transaction price divided by the size of the unit (in 1000 January $2014 \mathrm{~S} \$$ per $\mathrm{m}^{2}$ ). See the notes to Table 2 for variable definitions. Nonlinear least squares estimates. Standard errors, in parentheses, are clustered by building. Solver Knitro using interior-point algorithm with $\gamma_{1}$ fixed at 0.04 (i.e., $4 \%$ p.a.). All estimates are robust to optimization with a global search algorithm (Matlab's fminsearch), and are based on the full sample. 
Table 7: Sensitivity analysis: Varying the sample composition.

\begin{tabular}{|c|c|c|c|c|}
\hline Sample: & $\begin{array}{l}\text { Full } \\
(1)\end{array}$ & $\begin{array}{l}\text { Drop } \\
56-99 \\
\text { leases } \\
(2)\end{array}$ & $\begin{array}{c}\text { Only zips } \\
\text { w/ } 825-986 \\
\& \text { freehold } \\
(3)\end{array}$ & $\begin{array}{c}\text { Only zips } \\
\text { with all } \\
\text { lease types } \\
\text { (4) }\end{array}$ \\
\hline & \multicolumn{4}{|c|}{ Functional form: Exponential } \\
\hline$\gamma_{2}$ (slope parameter) & $\begin{array}{l}-0.0046 \\
(0.0003)\end{array}$ & $\begin{array}{l}-0.0050 \\
(0.0002)\end{array}$ & $\begin{array}{l}-0.0050 \\
(0.0002)\end{array}$ & $\begin{array}{c}-0.0051 \\
(0.0003)\end{array}$ \\
\hline 1-(mean $\left.\hat{\phi}_{i} 825-986\right) /\left(\right.$ mean $\hat{\phi}_{i}$ freehold $)$ & 0.059 & 0.106 & 0.103 & 0.124 \\
\hline 1-(mean $\left.\hat{\phi}_{i} 87-99\right) /\left(\right.$ mean $\hat{\phi}_{i}$ freehold $)$ & 0.138 & - & 0.187 & 0.211 \\
\hline $\operatorname{RSS}(/ \mathrm{N})$ & 7.0581 & 9.7315 & 7.8672 & 9.3480 \\
\hline \multirow[t]{2}{*}{$\mathrm{R}^{2}$} & 0.7692 & 0.7464 & 0.7724 & 0.7699 \\
\hline & \multicolumn{4}{|c|}{ Functional form: Semi-log } \\
\hline$\gamma_{2}$ (slope parameter) & $\begin{array}{l}-0.0095 \\
(0.0016)\end{array}$ & $\begin{array}{l}-0.0128 \\
(0.0001)\end{array}$ & $\begin{array}{l}-0.0126 \\
(0.0002)\end{array}$ & $\begin{array}{l}-0.0127 \\
(0.0002)\end{array}$ \\
\hline 1-(mean $\left.\hat{\phi}_{i} 825-986\right) /\left(\right.$ mean $\hat{\phi}_{i}$ freehold $)$ & 0.000 & 0.106 & 0.066 & 0.082 \\
\hline 1 - $\left(\right.$ mean $\left.\hat{\phi}_{i} 87-99\right) /\left(\right.$ mean $\hat{\phi}_{i}$ freehold $)$ & 0.130 & - & 0.305 & 0.321 \\
\hline $\operatorname{RSS}(/ \mathrm{N})$ & 7.0724 & 9.7309 & 7.8979 & 9.4383 \\
\hline \multirow[t]{2}{*}{$\mathrm{R}^{2}$} & 0.7688 & 0.7464 & 0.7715 & 0.7677 \\
\hline & \multicolumn{4}{|c|}{ Functional form: Hyperbolic } \\
\hline$\gamma_{2}$ (slope parameter) & $\begin{array}{l}-0.1396 \\
(0.0308)\end{array}$ & $\begin{array}{c}-0.4276 \\
(0.0113)\end{array}$ & $\begin{array}{c}-0.1884 \\
(0.0487)\end{array}$ & $\begin{array}{c}-0.1793 \\
(0.0386)\end{array}$ \\
\hline 1-(mean $\left.\hat{\phi}_{i} 825-986\right) /\left(\right.$ mean $\hat{\phi}_{i}$ freehold $)$ & 0.000 & 0.113 & 0.000 & 0.000 \\
\hline 1 - $\left(\right.$ mean $\left.\hat{\phi}_{i} 87-99\right) /\left(\right.$ mean $\hat{\phi}_{i}$ freehold $)$ & 0.130 & - & 0.196 & 0.183 \\
\hline $\operatorname{RSS}(/ \mathrm{N})$ & 7.0722 & 9.7109 & 7.9601 & 9.5140 \\
\hline $\mathrm{R}^{2}$ & 0.7688 & 0.7469 & 0.7697 & 0.7658 \\
\hline Observations & 179,218 & 81,988 & 31,072 & 22,751 \\
\hline
\end{tabular}

Notes: The estimating equation is based on additively separable errors and housing-service utility that is linear in parameters. The dependent variable is the property's transaction price divided by the size of the unit (in 1000 January $2014 \mathrm{~S} \$$ per $\mathrm{m}^{2}$ ). See the notes to Table 2 for variable definitions. Nonlinear least squares estimates. Standard errors, in parentheses, are clustered by building. Solver Knitro using interior-point algorithm with $\gamma_{1}$ and $\gamma_{3}$ fixed at 0.04 and 0.0001 (i.e., $4 \%$ and $0.01 \%$ p.a.), respectively. All estimates are robust to optimization with a global search algorithm (Matlab's fminsearch). Column (1) uses the full sample. Column (2) restricts the sample to purchases of 825 to 986 -year leases or of freeholds. Column (3) (resp., (4)) considers purchases of any lease type but only in 3-digit zip codes with both 825 to 986-year lease and freehold types (resp., with all three lease types). Table 1 lists the composition of samples. 
Table 8: (Structural) Alternative assumption on unobservables (and exponential rate schedule).

\begin{tabular}{|c|c|c|c|c|}
\hline Sample: & $\begin{array}{c}\text { Full } \\
(1)\end{array}$ & $\begin{array}{c}\text { Drop } \\
56-99 \\
\text { leases } \\
(2)\end{array}$ & $\begin{array}{c}\text { Only zips } \\
\text { w/ 825-986 } \\
\text { \& freehold } \\
(3)\end{array}$ & $\begin{array}{c}\text { Only zips } \\
\text { with all } \\
\text { lease types } \\
(4)\end{array}$ \\
\hline $\begin{array}{l}\text { Rate schedule parameters: } \\
\gamma_{1} \text { (year-1 discount rate, p.a.) }\end{array}$ & Fix at 0.04 & Fix at 0.04 & Fix at 0.04 & Fix at 0.04 \\
\hline$\gamma_{2}$ (slope parameter) & $\begin{array}{l}-0.0044 \\
(0.0001)\end{array}$ & $\begin{array}{l}-0.0046 \\
(0.0002)\end{array}$ & $\begin{array}{l}-0.0047 \\
(0.0001)\end{array}$ & $\begin{array}{l}-0.0047 \\
(0.0001)\end{array}$ \\
\hline \multicolumn{5}{|l|}{ Housing-services utility parameters: } \\
\hline Unit size $\left(\mathrm{m}^{2} / 100\right)$ & $\begin{array}{c}-70.09 \\
(5.49)\end{array}$ & $\begin{array}{l}-67.85 \\
(8.13)\end{array}$ & $\begin{array}{l}-95.36 \\
(12.41)\end{array}$ & $\begin{array}{l}-55.92 \\
(10.36)\end{array}$ \\
\hline Unit size squared $\left(\mathrm{m}^{4} / 10^{4}\right)$ & $\begin{array}{l}13.37 \\
(1.65)\end{array}$ & $\begin{array}{l}14.72 \\
(2.68)\end{array}$ & $\begin{array}{l}24.60 \\
(3.66)\end{array}$ & $\begin{array}{l}14.62 \\
(3.33)\end{array}$ \\
\hline Floor $(/ 10)$ & $\begin{array}{l}11.80 \\
(3.53)\end{array}$ & $\begin{array}{l}22.53 \\
(4.84)\end{array}$ & $\begin{array}{l}13.02 \\
(4.46)\end{array}$ & $\begin{array}{l}13.30 \\
(4.12)\end{array}$ \\
\hline Floor squared $(/ 100)$ & $\begin{array}{l}7.05 \\
(1.77)\end{array}$ & $\begin{array}{l}4.58 \\
(2.78)\end{array}$ & $\begin{array}{c}3.04 \\
(1.94)\end{array}$ & $\begin{array}{l}1.67 \\
(1.80)\end{array}$ \\
\hline First floor of building (1=yes) & $\begin{array}{l}-16.70 \\
(1.52)\end{array}$ & $\begin{array}{l}-15.97 \\
(1.62)\end{array}$ & $\begin{array}{l}-15.85 \\
(1.97)\end{array}$ & $\begin{array}{l}-9.47 \\
(1.81)\end{array}$ \\
\hline Top floor of building (1=yes) & $\begin{array}{r}-25.56 \\
(1.39)\end{array}$ & $\begin{array}{l}-30.09 \\
(2.13)\end{array}$ & $\begin{array}{l}-20.61 \\
(2.07)\end{array}$ & $\begin{array}{l}-13.93 \\
(2.13)\end{array}$ \\
\hline Project size $(/ 100)$ & $\begin{array}{c}0.32 \\
(1.88)\end{array}$ & $\begin{array}{l}-1.27 \\
(3.34)\end{array}$ & $\begin{array}{l}-7.02 \\
(3.19)\end{array}$ & $\begin{array}{c}3.32 \\
(2.75)\end{array}$ \\
\hline Project size squared $\left(/ 10^{4}\right)$ & $\begin{array}{l}-0.07 \\
(0.21)\end{array}$ & $\begin{array}{l}-0.28 \\
(0.41)\end{array}$ & $\begin{array}{c}0.26 \\
(0.31)\end{array}$ & $\begin{array}{l}-0.59 \\
(0.26)\end{array}$ \\
\hline Purchase-completion year bins & Yes & Yes & Yes & Yes \\
\hline 3-digit zip code fixed effects & Yes & Yes & Yes & Yes \\
\hline Larger land parcel dummy & Yes & Yes & Yes & Yes \\
\hline Purchase year fixed effects & Yes & Yes & Yes & Yes \\
\hline Quarter-of-year fixed effects & Yes & Yes & Yes & Yes \\
\hline 1-(mean $\left.\hat{\phi}_{i} 825-986\right) /\left(\right.$ mean $\hat{\phi}_{i}$ freeh. $)$ & 0.043 & 0.058 & 0.066 & 0.070 \\
\hline 1-(mean $\left.\hat{\phi}_{i} 87-99\right) /\left(\right.$ mean $\hat{\phi}_{i}$ freeh. $)$ & 0.119 & - & 0.146 & 0.151 \\
\hline $\operatorname{RSS}(/ \mathrm{N})$ & 0.0235 & 0.0268 & 0.0246 & 0.0237 \\
\hline $\mathrm{R}^{2}$ & 0.8383 & 0.8192 & 0.8373 & 0.8599 \\
\hline Observations & 179,218 & 81,988 & 31,072 & 22,751 \\
\hline $\begin{array}{l}\text { Totes: The estimating equation is "log.lin.," } \\
\text { transaction price divided by the size of } \\
\text { utility is linear in parameters. See the } \\
\text { estimates. Standard errors, in parenthe } \\
\text { algorithm with } \gamma_{1} \text { and } \gamma_{3} \text { fixed at } 0.04 \text { ar } \\
\text { between }-0.1 \text { and } 0.1 \text {. Column (1) uses } \\
825 \text { to } 986 \text {-year leases or of freeholds. } \\
\text { only in } 3 \text {-digit zip codes with both } 825 \\
\text { types). Table } 1 \text { lists the composition of }\end{array}$ & $\begin{array}{l}\text { ere the depend } \\
\text { e unit (in } 1000 \\
\text { tes to Table } 2 \\
\text {, are clustered } \\
0.0001 \text { (i.e., } 4 \% \\
\text { e full sample. } \\
\text { umn (3) (resp. } \\
\text { 986-year lease } \\
\text { mples. }\end{array}$ & $\begin{array}{l}\text { ent variable is } \\
\text { January } 2014 \text { s } \\
\text { for variable defi } \\
\text { by building. So } \\
\text { and } 0.01 \% \text { p.a. } \\
\text { Column (2) rest } \\
\text { (4)) considers } \\
\text { and freehold t }\end{array}$ & $\begin{array}{l}\text { logarithm of } \\
\text { per } \mathrm{m}^{2} \text { ), and } \\
\text { tions. Nonlinea } \\
\text { ver Knitro usin } \\
\text { respectively. } \gamma \\
\text { cts the sample } \\
\text { urchases of any } \\
\text { pes (resp., with }\end{array}$ & $\begin{array}{l}\text { the property's } \\
\text { housing-service } \\
\text { ar least squares } \\
\mathrm{g} \text { interior-point } \\
2 \text { is constrained } \\
\text { to purchases of } \\
\text { lease type but } \\
\text { all three lease }\end{array}$ \\
\hline
\end{tabular}




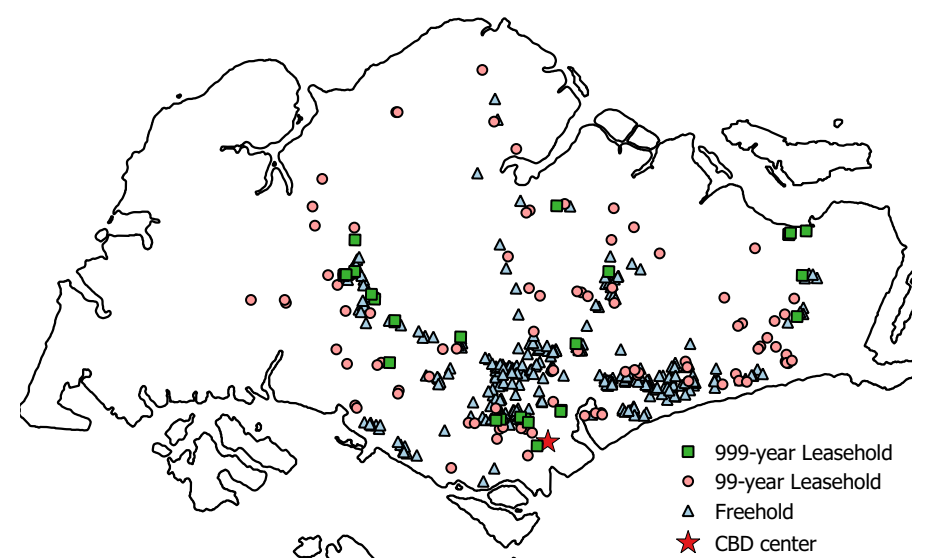

(a) Projects with condominiums sold in 1995-1999

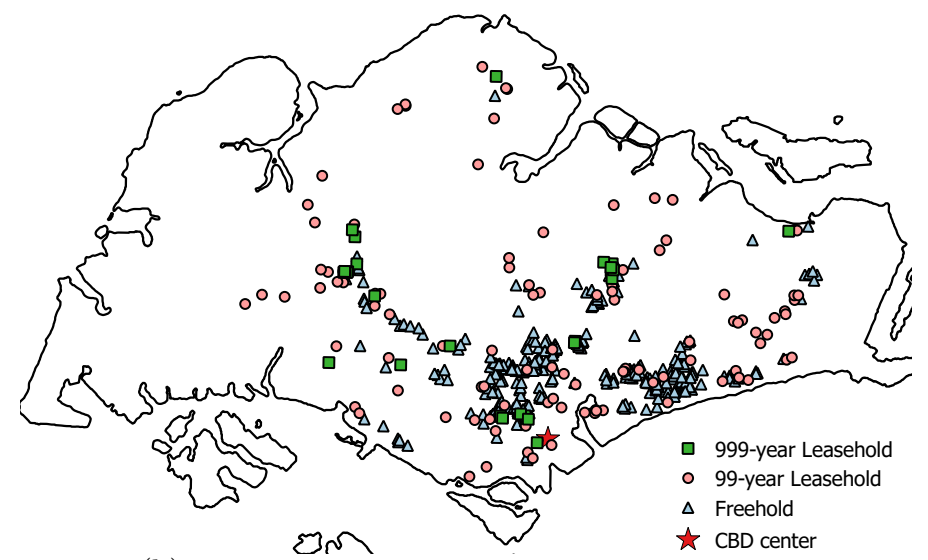

(b) Projects with condominiums sold in 2000-2004

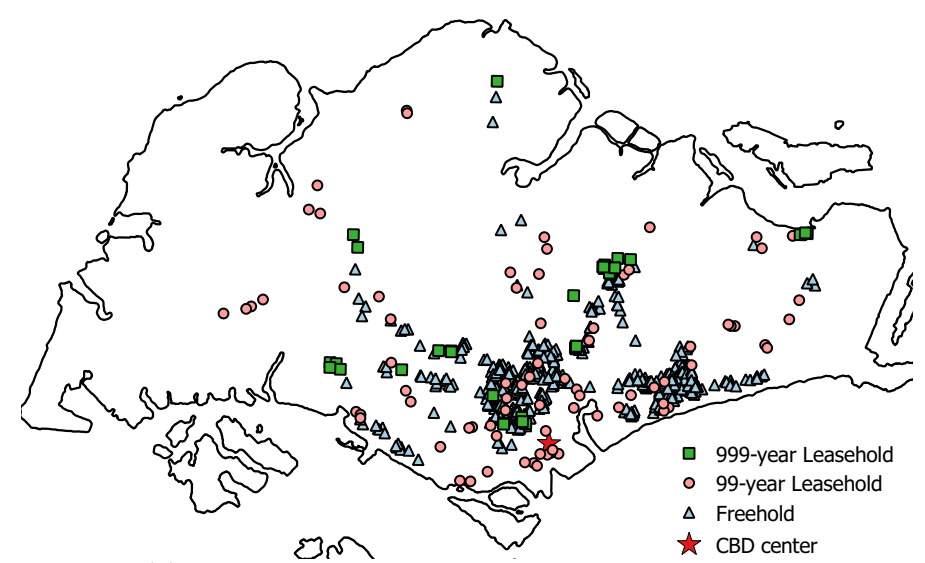

(c) Projects with condominiums sold in 2005-2009

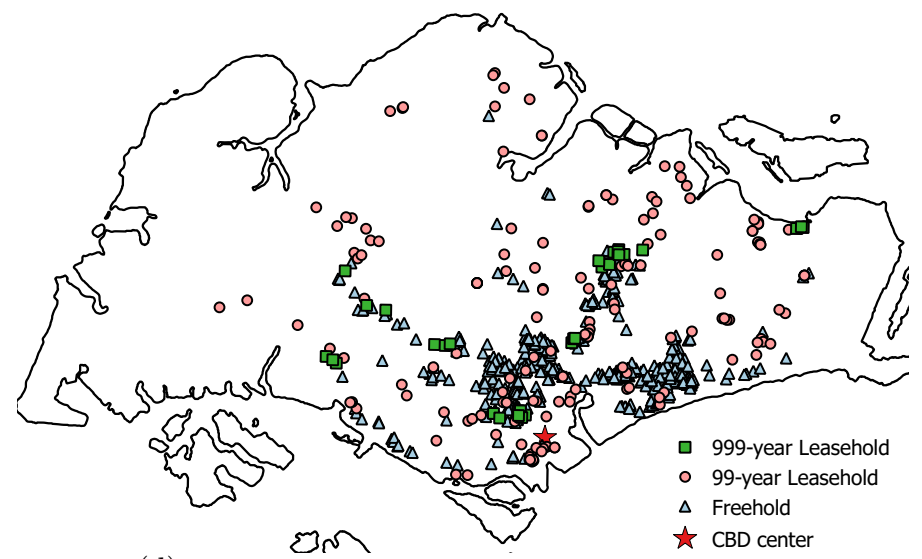

(d) Projects with condominiums sold in 2010-2015

Figure 1: Project location by tenure and period of sale 


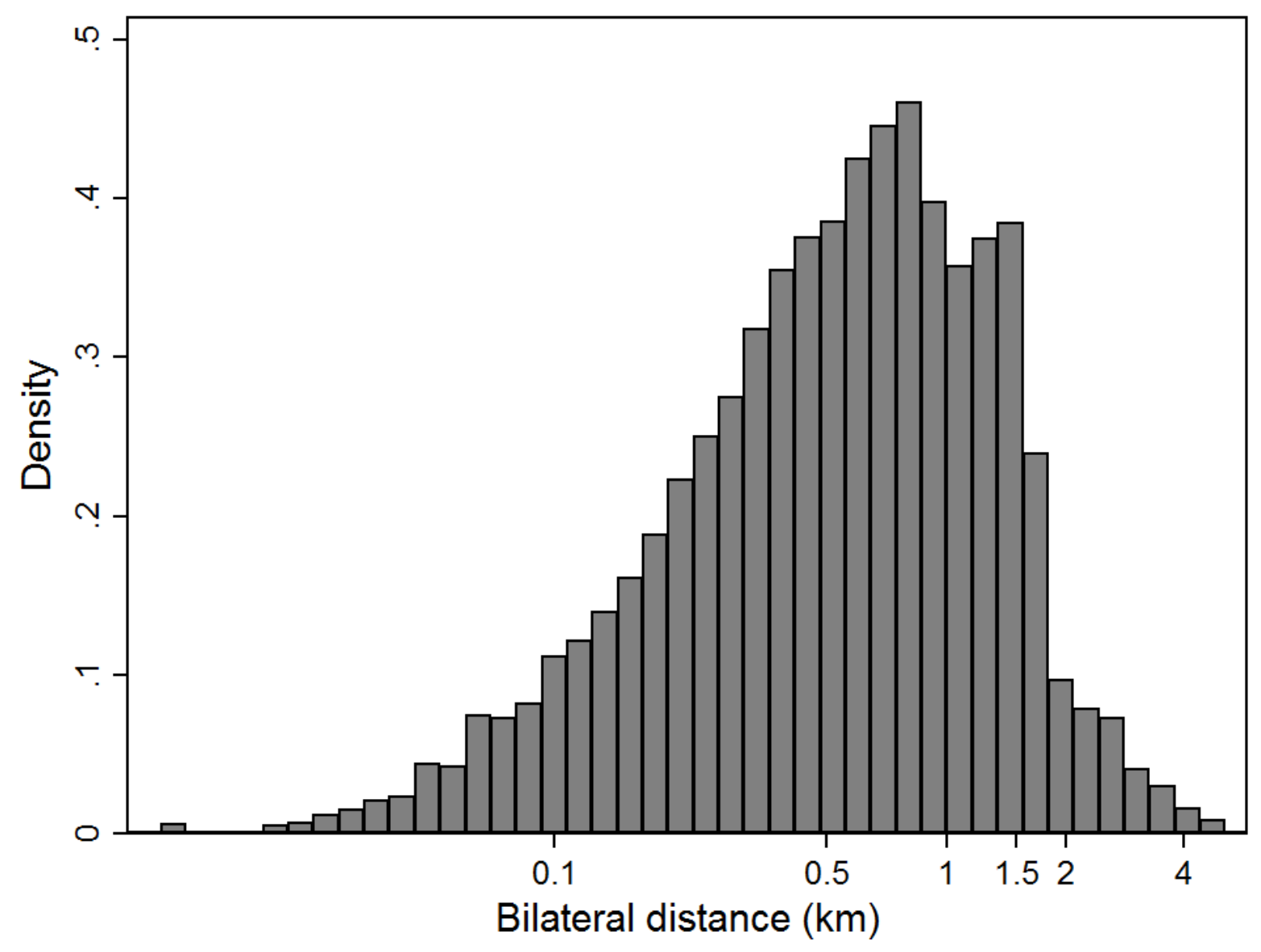

Figure 2: Bilateral distance between project pairs with the same three-digit zip code 


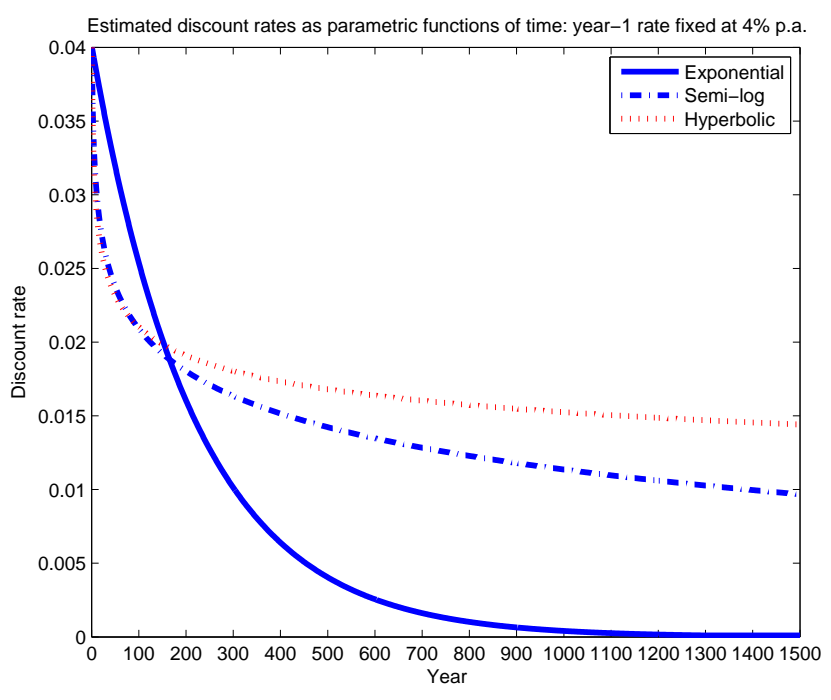

(a) Discount rates, time in linear scale

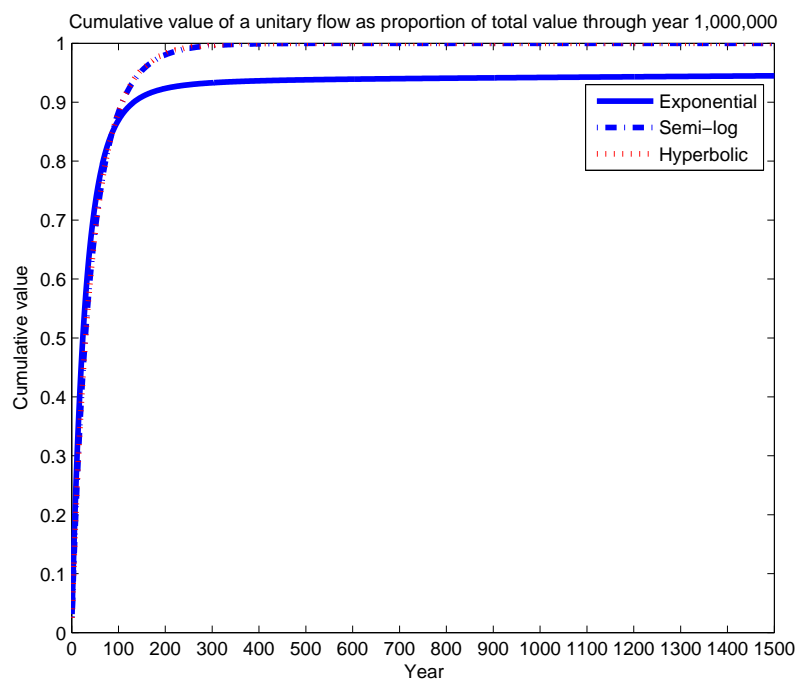

(c) Cumulative value, time in linear scale

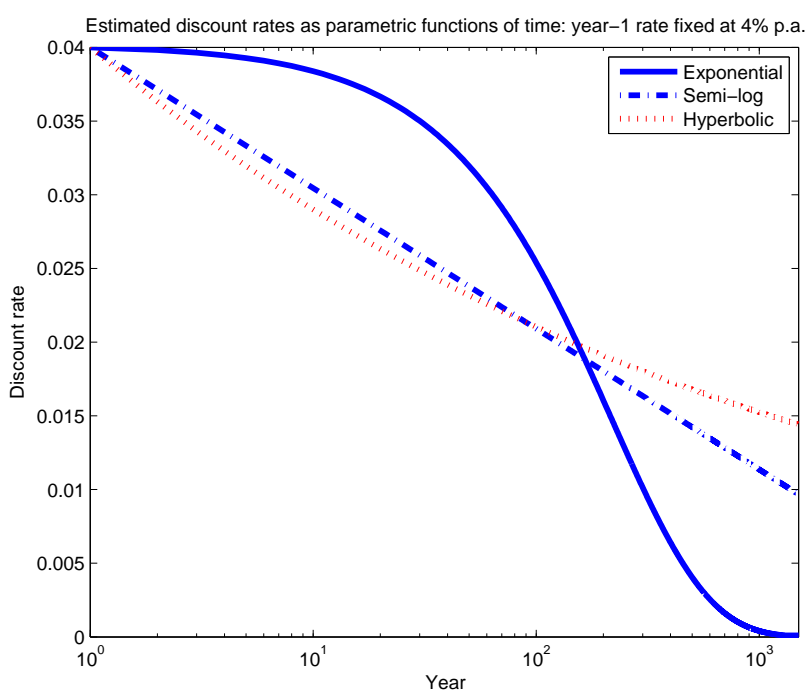

(b) Discount rates, time in logarithmic scale

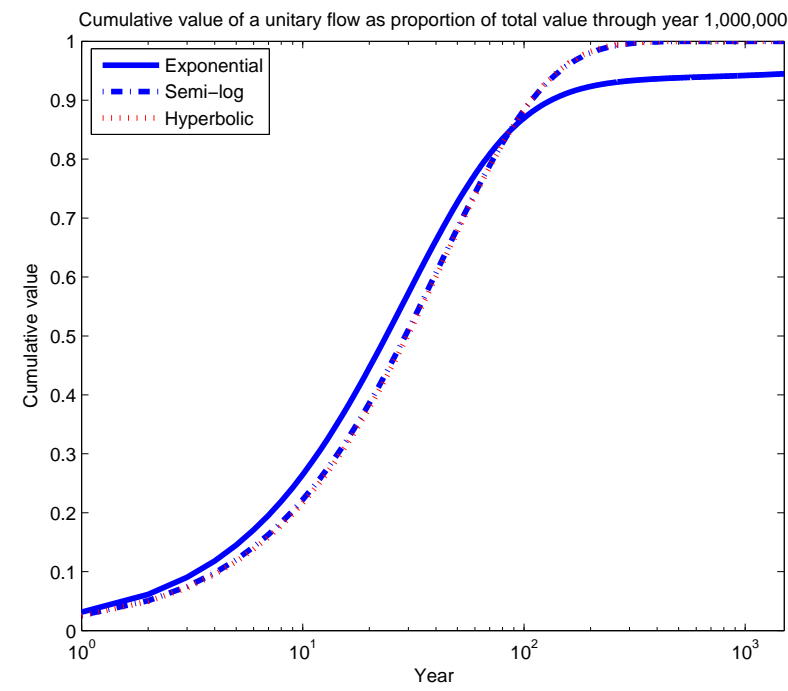

(d) Cumulative value, time in logarithmic scale

Figure 3: Estimated declining discount rates, in (a) linear and (b) logarithmic time scales. The discount rate, $r_{t}$, discounts benefits from year $t+1$ to year $t$. Cumulative value of a unitary flow each year as a proportion of the total value through year 1,000,000, in (c) linear and (d) logarithmic time scales. Varying the parametric function within panel. Source: Estimates, based on the full sample, from Table 4, columns (1) to (3), with year- 1 rate, $\gamma_{1}$, and lower bound, $\gamma_{3}$, fixed at $4 \%$ p.a. and $0.01 \%$ p.a., respectively. 


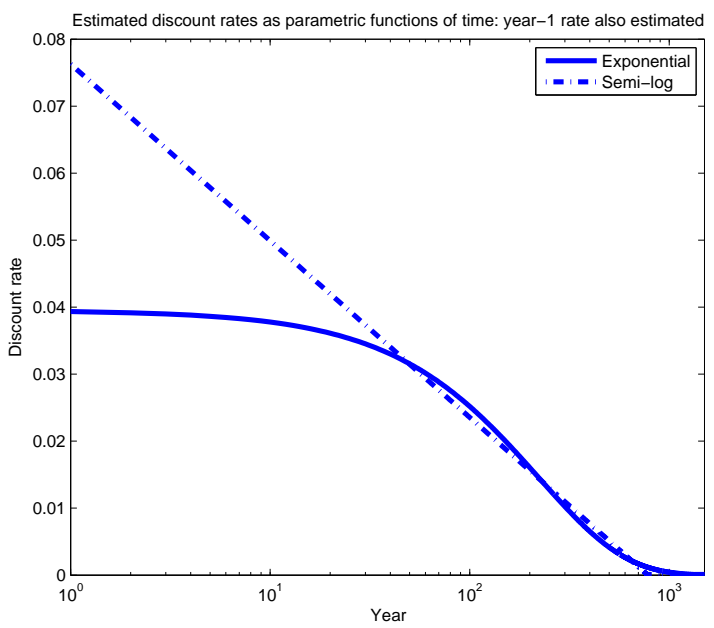

Figure 4: Estimated declining discount rates, when estimating the year-1 rate, $\gamma_{1}$, along with the slope parameter, $\gamma_{2}$. The discount rate, $r_{t}$, discounts benefits from year $t+1$ to year $t$. Varying the parametric function within panel. Time in logarithmic scale. Source: Estimates, based on the full sample, from Table 4 , columns (4) and (5), with lower bound, $\gamma_{3}$, fixed at $0.01 \%$ p.a.. 


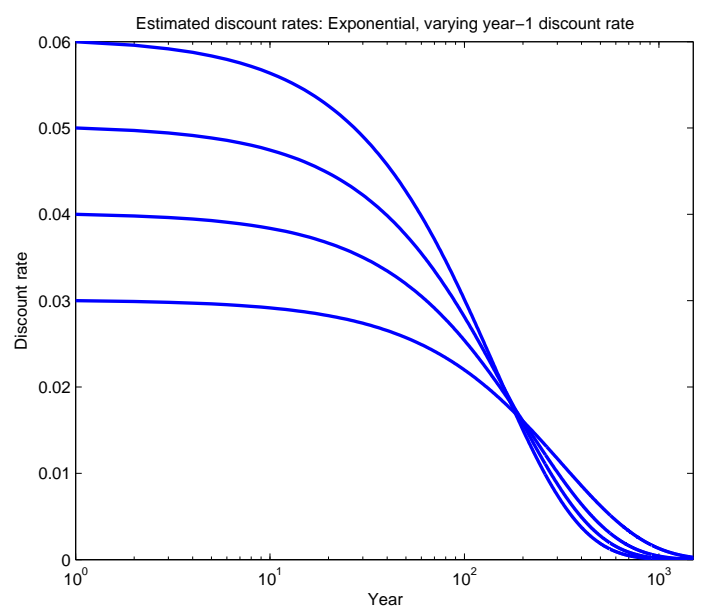

(a) Discount rates, exponential form

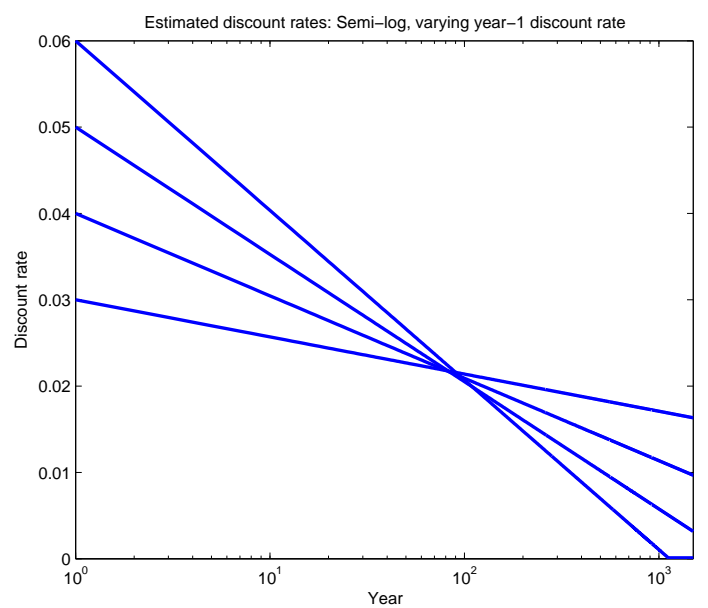

(b) Discount rates, semi-log form

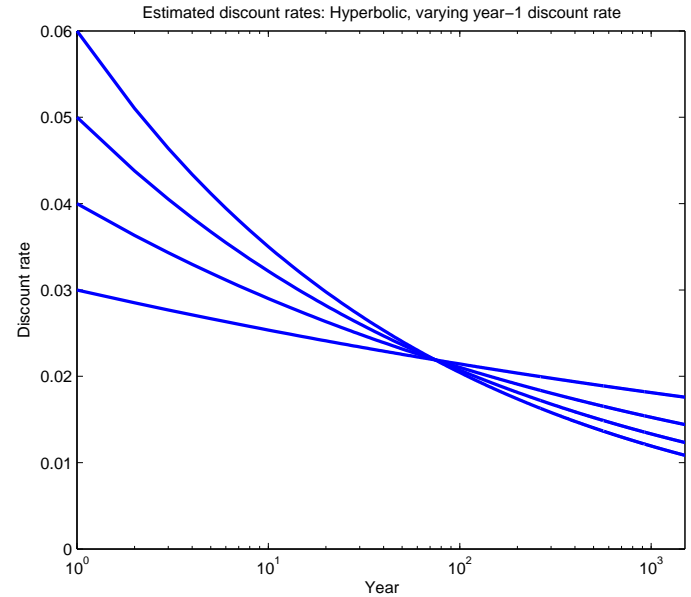

(c) Discount rates, hyperbolic form

Figure 5: Estimated declining discount rates as the year-1 rate, $\gamma_{1}$, varies for the different parametric forms: (a) exponential, (b) semi-log, and (c) hyperbolic. The discount rate, $r_{t}$, discounts benefits from year $t+1$ to year $t$. Time in logarithmic scale. Source: Estimates, based on the full sample, from Table 5, with lower bound, $\gamma_{3}$, fixed at $0.01 \%$ p.a.. 


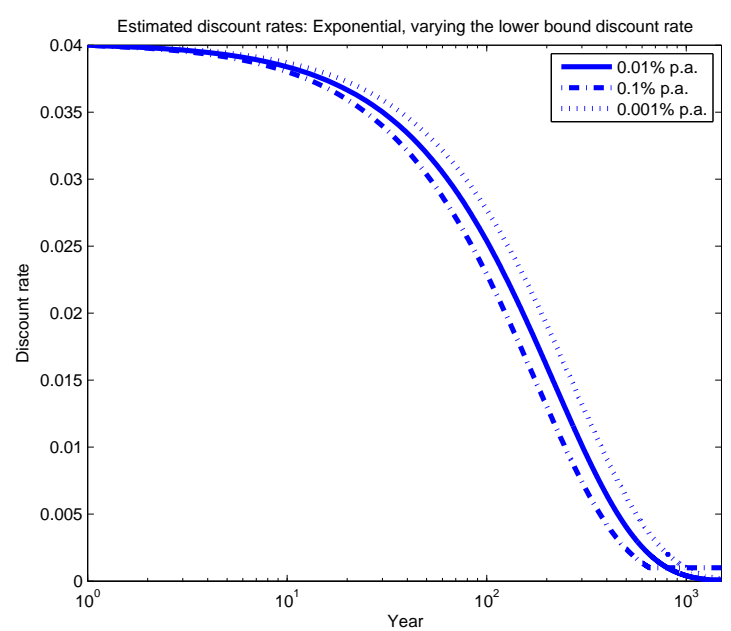

Figure 6: Estimated declining discount rates as the lower bound to the discount rate, $\gamma_{3}$, varies. The discount rate, $r_{t}$, discounts benefits from year $t+1$ to year $t$. Exponential form (no change for the other functional forms). Time in logarithmic scale. Source: Estimates, based on the full sample, from Table 6, with year- 1 rate, $\gamma_{1}$, fixed at $4 \%$ p.a.. 


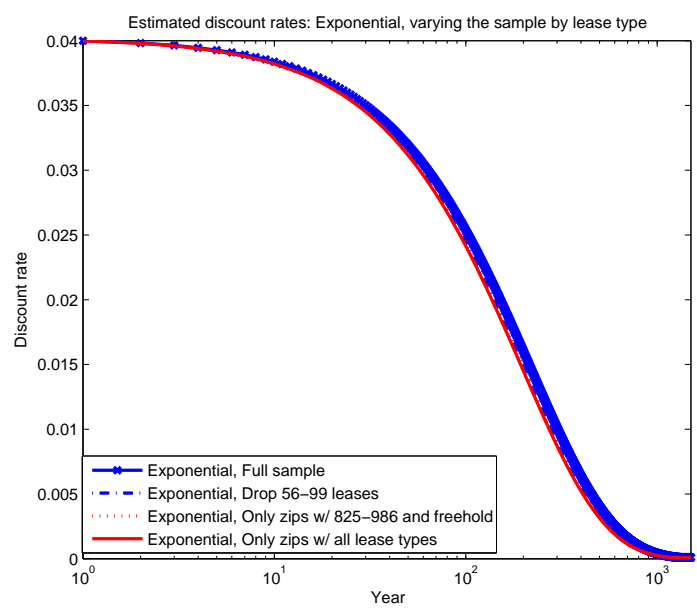

(a) Discount rates, exponential form

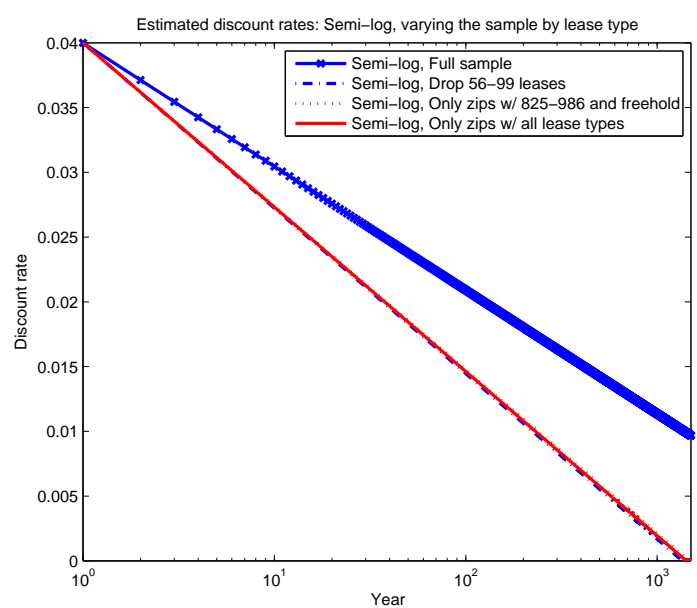

(b) Discount rates, semi-log form

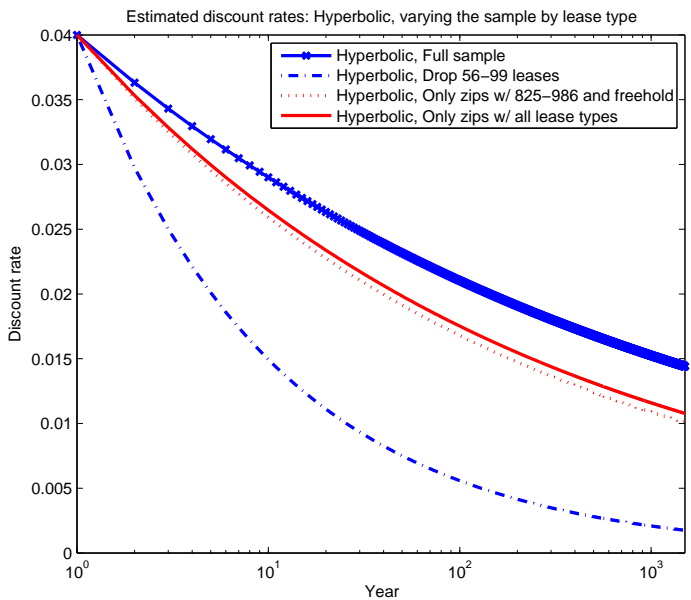

(c) Discount rates, hyperbolic form

Figure 7: Estimated declining discount rates, as the sample composition varies, within panel, for the different parametric forms: (a) exponential, (b) semi-log, and (c) hyperbolic. The discount rate, $r_{t}$, discounts benefits from year $t+1$ to year $t$. Time in logarithmic scale. Source: Estimates from Table 7, with year-1 rate, $\gamma_{1}$, and lower bound, $\gamma_{3}$, fixed at $4 \%$ p.a. and $0.01 \%$ p.a., respectively. 


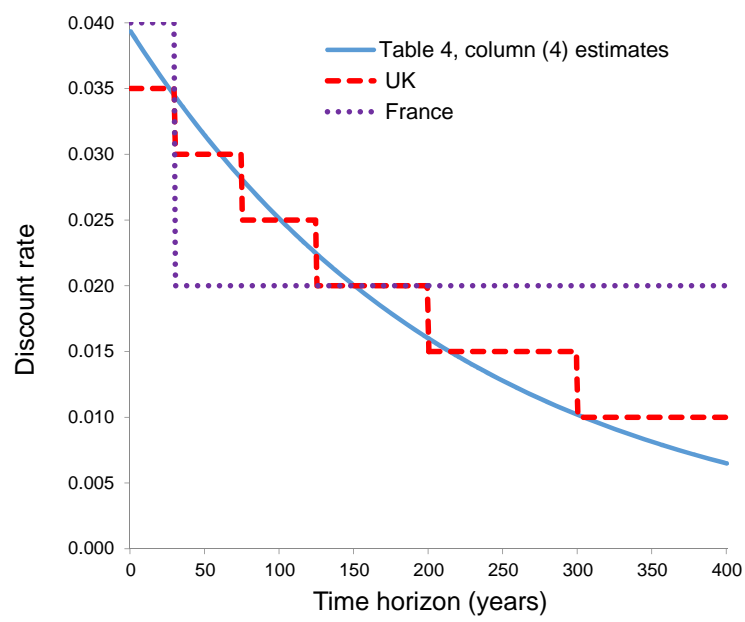

(a) Estimated discount rates versus UK and France discounting policy schedules

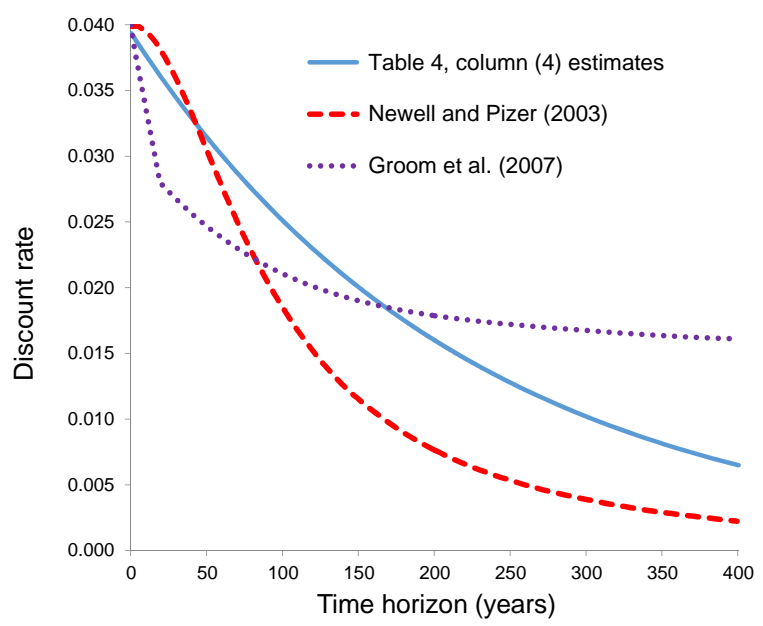

(b) Estimated discount rates versus Newell and Pizer (2003) and Groom et al. (2007), random-walk and state-space models, respectively

Figure 8: Estimated declining discount rates, based on the specification in column (4), Table 4, compared to discount rate schedules ("forward rates"): (a) used by the governments of the UK and France to evaluate climate change policy (HM Treasury, 2003; Lebègue, 2005), and (b) estimated by Newell and Pizer (2003) (autoregressive random walk) and Groom et al. (2007) (autoregressive process with time-dependent parameters). The discount rate, $r_{t}$, discounts benefits from year $t+1$ to year $t$. Time in linear scale. We thank Richard Newell and Billy Pizer for sending us their simulated discount factors, from which we computed the plotted discount rate schedule. Groom et al. discount rates were obtained from an earlier working paper, Groom et al. (2004), Table 2, that listed certainty-equivalent discount rates for an illustrative grid of horizons, to which we fitted smooth polynomials for the purpose of plotting the rate schedule. 


\section{Appendix}

\section{A.1 Sample composition}

The REALIS database comprises all private residential property transactions for which caveats were lodged with the Singapore Land Authority. A caveat is a legal document lodged by a purchaser or his/her mortgage provider to protect his/her interests in that property by preventing further contradictory dealings with the property from being registered. Only a very small proportion of transactions do not see a caveat lodged. In particular, buyers who do not take out a mortgage are not required to lodge a caveat, although many still choose to. In addition to losing transactions without lodged caveats, we also exclude multi-unit transactions, which account for about $1 \%$ of our sample. We do so because we do not have information on individual property characteristics, such as floor number and unit size.

To check our sample coverage, we compare the number of units that appear in our sales data set with the total number of constructed units. The latter information is available from REALIS for condominium projects whose construction was completed beginning in the second quarter of 2002. Because it might take the developer several years to sell all units in a project, we focus on the 735 projects that were completed between 2003 and 2012 and have at least one recorded transaction. Out of a universe of 82,991 constructed units for these 735 projects, we observe the sale of 77,095 units in our transaction data, or $93 \%$ of the population. Another way to check our sample coverage is to compare the changes in the stock of condominiums reported by URA against the number of new condominium transactions observed in our sample, as we do in the text.

\section{A.2 Controlling for geographic variation}

Singapore uses a six-digit postal (zip) code system, with each apartment building associated with a unique six-digit zip code. We thus face a trade-off when specifying the granularity of our geographic controls. Specifying zip code fixed effects that are too detailed - for an extreme example, consider the six-digit level — would absorb the variation in remaining tenure that we seek to exploit. ${ }^{22}$ On the other hand, specifying geographic controls that are too coarse might lead to inconsistent estimates

\footnotetext{
${ }^{22}$ Note that even a condominium project, often comprising several buildings, thus consists of several buildingspecific six-digit zip codes - and, conditional on time of purchase (time fixed effect), no variation in remaining lease.
} 
of the effect of tenure on value, since tenure might correlate with unobserved quality differences from location.

To allow for enough variation in tenure type while controlling for geographic variation, we group properties by the first three digits of the zip code. Doing so results in 187 three-digit zip code areas, of which 108 of them have properties of different tenure types, i.e., freeholds, 999-year leaseholds, 99-year leaseholds. Among the 79 areas in which there is no variation in tenure type, e.g., all units are 99-year leaseholds, 30 areas contain only one condominium project. Observations from these areas can only be used to identify housing-services utility parameters and market fixed effects, but not rate schedule parameters. Importantly, if we specify five-digit zip code fixed effects as GMS do in their analysis of new and used properties - see Appendix A.5 below - then our sample of 1,672 condominium projects would be divided into 1,516 regions. Clearly, 1,516 five-digit zip code fixed effects would absorb most of the price variation across tenure type - unless variation in price were arising also from variation in age in a sample that, as in GMS, included used condominium transactions, e.g., purchases of a new condominium on a 95-year lease alongside a used condominium aged 10 years on a 85-year lease.

Given that the main island of Singapore measures $50 \mathrm{~km}$ from east to west and $27 \mathrm{~km}$ from north to south, and of which about $20 \%$ of its land is occupied by housing, dividing its residential area into 187 regions enables us to control for geographic variation at quite a granular level. To demonstrate this, we obtained the geographic coordinates for each of the 1,672 projects and calculated the bilateral distance between each pair of projects that share the same three-digit zip code. The distribution of these within-area bilateral distances is plotted in Figure 2: across pairs of properties with the same three-digit zip code, the majority is located in close proximity. Specifically, $75 \%$ of these bilateral distances are shorter than $1 \mathrm{~km}$ and $95 \%$ of the distances are shorter than $1.8 \mathrm{~km}$. In other words, $95 \%$ of the projects from the same three-digit zip code areas are located in an area with a $0.9 \mathrm{~km}$ radius. Moreover, only 8 projects (44 bilateral distances) are located more than $4 \mathrm{~km}$ away than other projects with a three-digit zip code in common. The evidence suggests that three-digit zip code fixed effects provides a good compromise between controlling for potentially confounding spatial heterogeneity and providing enough variation in tenure type. 


\section{A.3 Adjusting prices, including prepayments, to 2014 dollars}

Payment of the purchase price is due in full when a buyer purchases a condominium that is already completed. In this case, payment coincides with the start of housing benefits (and, as mentioned, we adjust the historical purchase price to January 2014 dollars). In contrast, when a buyer purchases a condominium that is still under development, partial payment is made prior to the start of housing benefits. Here, we take the observed time difference between purchase and construction completion, and adjust (compound) the transaction price using a typical payment scheme that developers have followed for transactions that take place before construction is complete. In particular, we adopt the scheme recommended under the current URA guidelines, noting that there has been little variation in prepayment schemes over the sample period and across developers.

Under the URA scheme, $20 \%$ of the purchase price is due upon signing the Sale \& Purchase agreement, or within 8 weeks from the Option to Purchase. Another $40 \%$ is due in gradual payments based on the completion of six staggered stages of construction. For example, $10 \%$ is due when the foundation is completed. Another $10 \%$ is due when the concrete framework is completed. At a subsequent stage, $25 \%$ is due when the Temporary Occupation Permit or Certificate of Statutory Completion is issued, and the final $15 \%$ is due soon after, upon building completion. These last two payments are typically due well within a year of each other.

We approximate this payment scheme and adjust the transaction price as follows. For a condominium purchase observed any year before the completion year, we adjust any amount due at the time of purchase for milestones that had already passed-e.g., the initial $20 \%$ deposit and any payments such as the $10 \%$ for foundation work-using the CPI of the purchase month-year (adjusted to January 2014 dollars). The $40 \%$ of the price due at or near completion is adjusted by the completion-year June CPI. (We do not observe the month of completion and take it to be June, as a midpoint.) Other intermediate payments - e.g., the $10 \%$ for concrete work - are adjusted by the (midpoint) June CPI of the years between the purchase year and the completion year.

How the remaining $60 \%$ beyond the $40 \%$ due in the completion year is adjusted depends on the number of years that elapse from purchase to construction completion. For a condominium purchase observed in March (say) a year before the completion year, we adjust the remaining $60 \%$ by the purchase-year March CPI. For a condominium purchase observed in March two years before the completion year, we adjust $50 \%$ of the price by the purchase-year March CPI and $10 \%$ by the 
year-after-purchase June CPI. For a condominium purchase observed in March three years before the completion year, we adjust $40 \%$ of the price by the purchase-year March CPI, $10 \%$ by the year-after-purchase June CPI, and $10 \%$ by the two-years-after-purchase June CPI. Finally, for a condominium purchase observed fours years or more before June of the completion year, we adjust $20 \%$ of the price by the purchase month-year CPI, $20 \%$ by the year-after-purchase June CPI, $10 \%$ by the two-years-after-purchase June CPI, and $10 \%$ by the three-years-after-purchase June CPI.

Again, any payments due at the time of purchase are adjusted by the CPI of the purchase month and year to January 2014 dollars. For example, for a condominium purchased in March, say, either in the year of or after completion, we adjust the entire purchase price by the March CPI of the purchase year since payment would have been due in full at the time of the purchase.

\section{A.4 Rental prices and unobserved heterogeneity}

Our purchase price regressions control for many observed property characteristics such as location, unit size and floor number, besides age and building type directly by choice of sample. Yet one may ask whether unobserved quality can differ systematically by tenure length. We look to the rental market for an indication of whether unobserved heterogeneity is important. Since renters should care only about flows of housing services and not differences in tenure, finding that tenure has no effect on rental prices provides evidence that properties of different tenure types do not differ in unobserved quality.

With this in mind we downloaded rental data from the Urban Redevelopment Authority. The data comprises rental contracts for privately developed apartments (condominiums) submitted to the Inland Revenue Authority of Singapore for Stamp Duty assessment (Appendix A.6) within the last 36 months at the time of the search (February 2012 to January 2015). It includes information on monthly rent and starting month of the rental contract, the project name and street, and the number of bedrooms. (We do not observe the building within the project.) We merged projectlevel information, such as tenure type, construction completion year, total number of units in the project, and the highest floor of the project from the REALIS transaction sales data.

To control for unobserved heterogeneity arising from differences in renovation, maintenance, and depreciation, and in line with our analysis of property purchase prices, we restrict the sample to rentals of condominiums that were aged at most five years at the time of rental. Further, we 
restrict the analysis to three-digit zip codes with rental contracts recorded for original 999-year leaseholds and at least one other tenure type over the three-year sample period. Given some extreme prices in the data (e.g., very low at $\mathrm{S} \$ 5.4 / \mathrm{m}^{2}$, very high at $\mathrm{S} \$ 260 / \mathrm{m}^{2}$ ), we trimmed the top and bottom $1 \%$ of the rental price distribution. The data do not distinguish between studio units and a multi-bedroom unit renting out one bedroom, so we drop rentals of single-bedroom rentals. The final sample consists of 6,649 rental contracts, of which $72 \%$ are freehold units, $22 \%$ are original 999-year leaseholds, and 6\% are 99-year leaseholds.

Table A.4 reports estimates of a regression with the logarithm of the monthly rental price (in $2014 \mathrm{~S} \$$ per $\mathrm{m}^{2}$ ) as the dependent variable. The estimates on the original 999-year leasehold dummy and the 99-year leasehold dummy are small and statistically insignificant (the omitted category corresponds to freeholds). Evidence from the rental market thus suggests that unobserved quality across properties of varying tenure types, particularly between multi-century leases and freeholds, is unlikely to be strong.

\section{A.5 Comparing GMS to what we find for Singapore}

To understand why we obtain a robust and statistically significant premium for freeholds over 999-year leaseholds, where GMS found none, we attempted to reproduce the GMS sample and replicate their results. We extracted all private housing transactions (413,750 observations) from REALIS, for new and used property, condominiums and houses, for the period of January 1995 to December 2013. As in our study, variables include the transaction price, original tenure contract, whether the property is new or used, the year construction was completed, the six-digit unique zip code associated with the building, and the land title type, i.e., "strata" for apartments, and mostly "land" for houses. Where tenure or zip code were missing, we imputed the characteristic using non-missing values for transacted properties in the same building or development project. We dropped 1,879 observations for which tenure, tenure starting year, or zip code is missing on all transacted property for the same development project over the sample period. We further dropped 831 records associated with multi-unit transactions. We imputed missing completion year for property purchased during construction from the date of first transaction for new property in the same building, considering that construction (reliably) takes about 4 years for condominiums and 2 years for houses. We dropped 26,501 observations for which completion year remained missing. 
Table A.5 describes our reproduction of the GMS sample, numbering 384,539 transactions, to be compared to Table IV in their paper, that lists 378,768 . While we judge the reproduced sample to track the GMS sample fairly well, there are some differences. These differences include 34,547 transactions for 2011 in our reproduced sample versus 25,221 transactions in GMS that same year. In our reproduced sample, $17 \%$ of purchased properties have a remaining tenure of 90-94 years compared to only $7 \%$ in the GMS sample. Relative to GMS, there may be differences in how we count tenure remaining at the time the keys are handed over and utility from housing services begins to flow (not when the property is purchased, which if new could precede delivery by several years), as well as in how we adjust nominal purchase prices to January 2014 S\$. Further, using complementary sources we may have been able to complete more observations that are missing construction completion year in the original REALIS data. ${ }^{23}$ We note that while GMS interpret the dummy variable "HDB" in the REALIS database to mean that the buyer is the Housing and Development Board, what this variable means is that the buyer - a household - currently lives in an HDB apartment - see the last panel of Table A.5. ${ }^{24}$ About $40 \%$ of the GMS sample corresponds to the purchase of used property - see the second panel.

Table A.6 reports our estimates using our reproduction of the GMS sample (384,539 transactions), to be compared to Table VI in their paper. Following the GMS specification, on controlling for highly granular five-digit zip code fixed effects, ${ }^{25}$ the price discount for new and used condominiums and houses with 813 to 994 years of lease remaining is not significantly different than zero relative to otherwise comparable freeholds. Specifically, estimates on the 813-994-year dummy of -0.006 (s.e. 0.020 ) and 0.002 (s.e. 0.022) in columns (1) and (2) of Table A.6 are comparable to -0.010 (s.e. 0.033 ) and -0.007 (s.e. 0.038) in columns (1) and (2) of GMS Table VI, respectively. We use somewhat coarser bins than GMS for the original 99-year leaseholds, and estimates are statistically comparable, e.g., column (1) estimates range between -0.176 (87-103 year, s.e. 0.025) and -0.300 (56-63 year, s.e. 0.151), compared to a somewhat wide range between -0.125 (95-99

\footnotetext{
${ }^{23}$ See the data section and Appendix A.3. For reproducibility, we will make address (including floor, unit, and zip code), project name, original tenure contract, purchase (transaction) date, construction completion year, and tenure remaining available. The remaining data such as prices, while proprietary, can be easily downloaded from REALIS.

${ }^{24}$ In their Table VI, column (4), GMS "focus on properties that were bought by private individuals (and not the HDB)" (p.26).

${ }^{25}$ In terms of fixed effects, GMS interact zip code with transaction time (year-quarter or year-month), building type, and title type. GMS take units inside developments on land parcels classified as "large" by URA to be a distinct building type. In columns (1) to (7) we follow suit and specify interactions. Thus the number of regressors in these columns is two orders of magnitude larger than in columns (8) and (9), e.g., 22,416 regressors in column (7) versus 228 in column (8). The ratio of the number of observations to number of regressors is only 3 in column (3), with month-of-year as the seasonal control.
} 
year, s.e. 0.042$)$ and -0.409 (50-69 year, s.e. 0.069) in GMS. ${ }^{26}$

In column (3), we continue specifying the GMS five-digit zip code fixed effects and, as in column (3) of GMS Table VI, restrict the sample to "properties that were built within 3 years of the transaction date." Compared to column (2), the point estimate on the 813-994-year lease dummy falls by 0.024 to -0.022 , though it remains insignificantly different from zero (s.e. 0.024). Importantly, when controlling for five-digit zip code, the price difference between freeholds and 21-55 or 56-63 year leaseholds cannot be identified, and the estimated discount on 64-86 year leaseholds is smaller than on 87-103 year leaseholds and insignificant. ${ }^{27}$

As explained, specifying five-digit zip code intercepts essentially accounts for development project, within which the original tenure contract is invariant - the coefficients on the tenure bins are then estimated off of within-property variation in remaining tenure as properties age. These two variables are highly correlated, and for a mechanical reason: with the passing of every year, a property depreciates on account of the ageing of the building as well as a shorter lease. GMS state that their specification includes 94,700 fixed effects (p.25), for a sample that includes about twice as many new property purchases. A condominium project - the most common building type by far - consists of hundreds of units and displays no variation in original tenure ("999 Yrs From 21/06/1877"). Recall that in our own sample of new condominium purchases, 1,672 projects would be divided into 1,516 five-digit zip codes.

In columns (4) and (5) of Table A.6, we repeat the same GMS specifications in columns (2) and (3) except for the key departure that we now specify three-digit zip code fixed effects. As we argued, these quite detailed controls strike a balance between controlling for unobserved geographic heterogeneity (Figure 2) and allowing for residual variation in tenure that is orthogonal to property age. We are now able to estimate a significant price discount, of about 7 log points, for 813 to 994-year leaseholds relative to freeholds, whether we use our replication of the full GMS sample, or restrict this to properties aged 3 years or less.

\footnotetext{
${ }^{26}$ Our purpose in Table A.6 is to bridge the difference between what GMS report for Singapore and what we report in our descriptive regressions. Thus, column (9), discussed below, is comparable to Table 2, column (3), based on a slightly longer sample period. A strength of the structural approach we propose is that we need not settle on bins that are somewhat arbitrary in the first place. We note that the lowest and highest lease lengths remaining among original 99-year leaseholds differ between what GMS report and our attempted reproduction of their sample, though this concerns few observations.

${ }^{27}$ We note that the number of observations in column (3) relative to column (2) drops by about 30,000 less in Table A.6 (from 384,539 to 259,011) than in GMS Table VI (from 378,768 to 223,810). Further, GMS report estimates on the dummies for the shorter leases, while in our replication attempt these price effects are subsumed into the highly detailed fixed effects.
} 
In column (6), we begin to control for the unit's floor number, and the estimate on the 813-994year dummy is now $-0.065 \log$ points and more precisely estimated, with a s.e. of 0.028 versus 0.033 in column (5). To the best of our understanding, GMS do not control for floor number despite most properties in their Singapore sample (unlike UK property) being in high-rise buildings. In column (7), we drop purchases of houses (and of "HDB executive condominiums," per the note to Table A.5), and the 813 to 994-year leasehold discount becomes even more precisely estimated, with a s.e. of 0.026 .

Finally, in columns (8) and (9), we further drop resales of used units aged up to 3 years from construction, however lightly used they might be, thus restricting the sample to new condominium units, i.e., the first purchase of each unit. To complete the bridge between GMS and our empirical model, we also allow prices to shift flexibly with the time difference between condominium purchase and construction completion - recall that this period averages three years. We further replace the interactions of three-digit zip code, year, month and larger land parcel fixed effects (as in GMS) by separate fixed effects (as in our descriptive and structural regression estimates). The number of regressors falls from 22,416 in column (7) to 228 in columns (8) and (9). Column (9) differs from column (8) in that the effect of unit size and project size is non-linear, rather than linear (as in GMS). Compared to column (7), the estimate on the 813 to 994-year leasehold discount reported in column (9) is smaller, at -0.036 , and the s.e. also shrinks, to 0.018 , with a p-value of 0.059 . Despite the shorter sample ending December 2013 rather than January 2015, column (9) estimates are similar to those of Table 2, column (3).

\section{A.6 Restrictions on HDB purchases, and taxes}

\section{HDB apartments}

Compared to the largely unrestricted private housing market, the government regulates the purchase of new and used HDB apartments. We briefly describe some key HDB regulations.

Only Singapore citizens can buy new HDB apartments, and HDB resales can be purchased by citizens and permanent residents. The price of new HDB apartments is heavily discounted, and as many as 13 different schemes provide additional subsidies. For example, the "Additional CPF Housing Grant" and the "Special CPF Housing Grant" each provide up to $\mathbf{\$} \$ 40,000$ in additional subsidies to eligible buyers. Along with these subsidies is an income ceiling, as the government 
attempts to push buyers to the private housing market. For example, average gross monthly household income cannot exceed $\mathrm{S} \$ 12,000$ to be eligible to buy an HDB apartment with 4 rooms or more.

These schemes come with other restrictions as well. For example, the most common scheme, the Public Scheme, targets families. The buyer must be at least 21 years old and either be married, living with parents, or, in the cases of widowed or divorced persons, have legal custody of children. Common to the purchase of both new and resale HDB flats is the restriction that the buyer cannot have owned private property either in Singapore or overseas in the past 30 months.

New HDB apartments have a Minimum Occupancy Period of five years. In the private housing market, there is no occupancy requirement, but property is subject to extra taxes if resold within four years of the date of purchase, presumably to curb "flipping." For example, selling a unit within one year of purchase is subject to an additional $16 \%$ tax.

\section{Stamp duty}

There are two types of ad valorem duties payable by buyers: Buyer's Stamp Duty (BSD), and Additional Buyer's Stamp Duty (ABSD). The BSD rate is $1 \%$ for the first $\mathrm{S} \$ 180,000,2 \%$ for the next $\mathrm{S} \$ 180,000$, and $3 \%$ for the remaining amount. The ABSD was introduced in December 2011 to curb property price growth, and raised in January 2013. The schedule of the ABSD is as follows.

\begin{tabular}{lcc}
\hline Buyer's Residency Status & Dec/2011 to Jan/2013 & After Jan/2013 \\
\hline Citizens, 1st property & Not applicable & Not applicable \\
Citizens, 2nd property & Not applicable & $7 \%$ \\
Citizens, 3rd and subsequent property & $3 \%$ & $10 \%$ \\
Permanent Residents, 1st property & Not applicable & $5 \%$ \\
Permanent Residents, 2nd and after & $3 \%$ & $10 \%$ \\
Foreigners, any property & $10 \%$ & $15 \%$ \\
\hline
\end{tabular}

Since there are only 314 observations with a transaction price below $\mathrm{S} \$ 360,000$, the combined BSD/ABSD marginal tax rate depends only on the buyer's residency status, not on the value of the property. After the introduction of ABSD in 2011, it is possible that increased progressivity of stamp duty on some non-citizen buyers, and foreigners in particular, may have dampened demand for higher-value properties. To the extent that this shift adversely affected the demand for perpetu- 
ities over comparable lower-value maturities, controlling for this shift would increase the estimated freehold premium even further. In a robustness test of our findings, we also drop purchases after December 2011 (or even a little earlier to account for expected policy changes) from the sample.

\section{Property tax}

Annual property tax is an increasing function of a property's Annual Value (AV). The Inland Revenue Authority of Singapore determines AV from market rental prices for rented-out units in the same or comparable development project (rent depends on the flow utility of housing services, but not on property tenure). For most of our sample period, until January 2014, the property tax rate for owner-occupied units was 0 for the first $\$ \$ 6,000,4 \%$ for the next $\$ \$ 59,000$, and $6 \%$ for the amount exceeding $\$ \$ 65,000$. Over the last few months in our sample, after January 2014-which we drop in a robustness test-property tax for owner-occupied units became more progressive: 0 for the first $\mathrm{S} \$ 8,000,4 \%$ for the next $\mathrm{S} \$ 47,000$, and the rate increases by $2 \%$ for every $\mathrm{S} \$ 15,000$ increase in AV until it reaches the maximum of $16 \%$. For non-owner-occupied units, the marginal tax rate is a flat $10 \%$. 


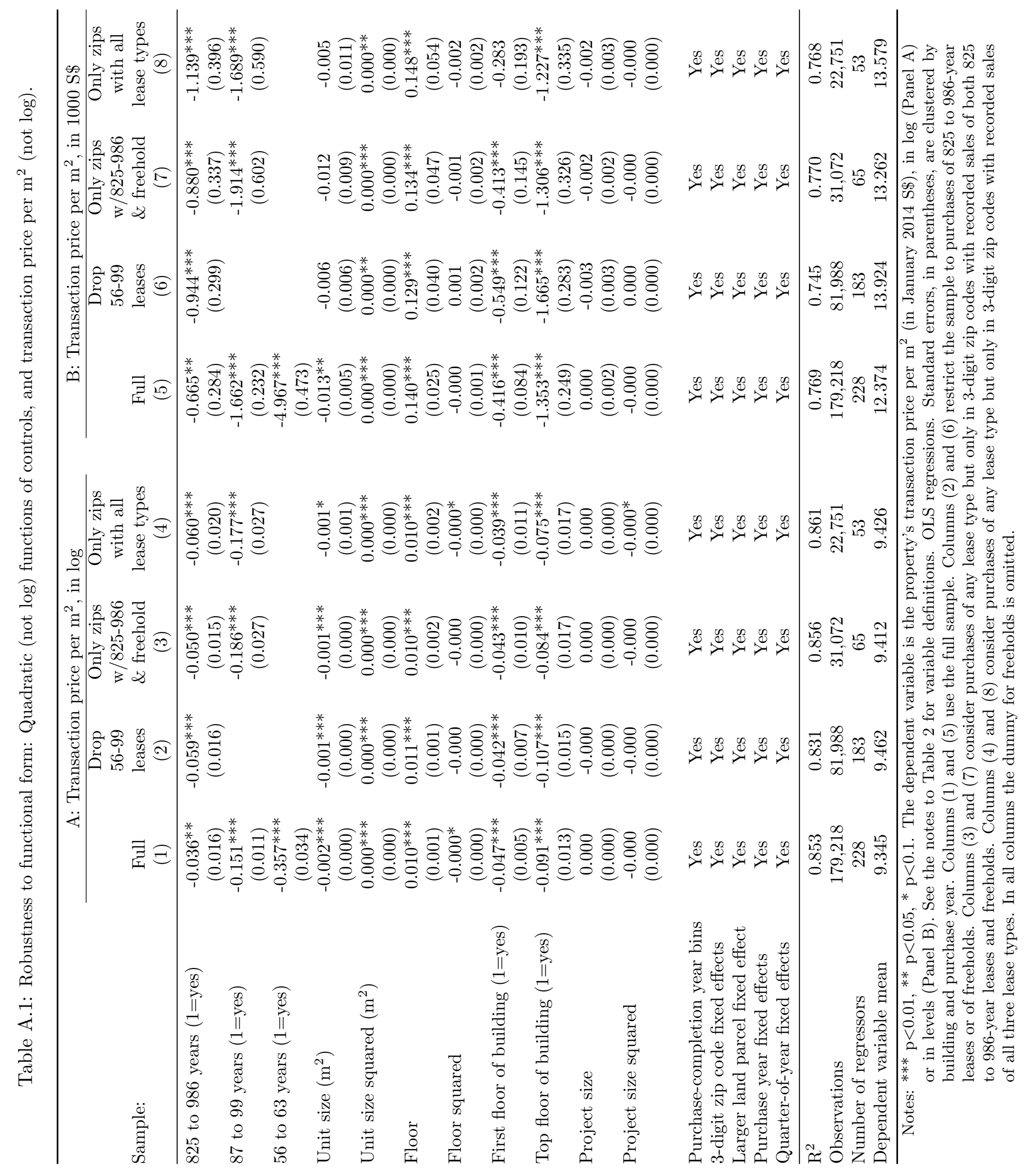


Table A.2: Robustness to sample composition: Transaction price per $\mathrm{m}^{2}$, in log. Various subsamples.

\begin{tabular}{|c|c|c|c|c|c|}
\hline Sample: & $\begin{array}{l}\text { Within } \\
0.5 \mathrm{~km} \text { of } \\
825-986 \\
(1)\end{array}$ & $\begin{array}{c}\text { Only zips } \\
\mathrm{w} / 825-986 \\
\geq 2 \text { types } \\
(2)\end{array}$ & $\begin{array}{l}\text { Drop top } \\
\text { and first } \\
\text { floors } \\
(3)\end{array}$ & $\begin{array}{c}\text { Construction } \\
\text { complete by } \\
2015 \\
(4)\end{array}$ & $\begin{array}{l}\text { Trim upper } \\
\& \text { lower } \\
1 \% \text { price } \\
(5)\end{array}$ \\
\hline 825 to 986 years $(1=$ yes $)$ & $\begin{array}{c}-0.057^{* * *} \\
(0.019)\end{array}$ & $\begin{array}{c}-0.053^{* * *} \\
(0.015)\end{array}$ & $\begin{array}{c}-0.043^{* *} \\
(0.017)\end{array}$ & $\begin{array}{c}-0.042^{* *} \\
(0.020)\end{array}$ & $\begin{array}{c}-0.042^{* * *} \\
(0.014)\end{array}$ \\
\hline 87 to 99 years $(1=$ yes $)$ & $\begin{array}{c}-0.238^{* * *} \\
(0.022)\end{array}$ & $\begin{array}{c}-0.205^{* * *} \\
(0.024)\end{array}$ & $\begin{array}{c}-0.157^{* * *} \\
(0.012)\end{array}$ & $\begin{array}{c}-0.139^{* * *} \\
(0.015)\end{array}$ & $\begin{array}{c}-0.168^{* * *} \\
(0.010)\end{array}$ \\
\hline 56 to 63 years $(1=$ yes $)$ & $\begin{array}{c}-0.384^{* * *} \\
(0.035)\end{array}$ & & $\begin{array}{c}-0.354^{* * *} \\
(0.040)\end{array}$ & $\begin{array}{c}-0.381^{* * *} \\
(0.090)\end{array}$ & $\begin{array}{c}-0.366^{* * *} \\
(0.036)\end{array}$ \\
\hline Unit size $\left(\log , \mathrm{m}^{2}\right)$ & $\begin{array}{c}-0.096^{* * *} \\
(0.020)\end{array}$ & $\begin{array}{c}-0.076^{* *} \\
(0.034)\end{array}$ & $\begin{array}{c}-0.066^{* *} \\
(0.027)\end{array}$ & $\begin{array}{c}-0.061^{* *} \\
(0.027)\end{array}$ & $\begin{array}{c}-0.133^{* * *} \\
(0.016)\end{array}$ \\
\hline Floor $(\log )$ & $\begin{array}{c}0.062^{* * *} \\
(0.007)\end{array}$ & $\begin{array}{c}0.063^{* * *} \\
(0.008)\end{array}$ & $\begin{array}{c}0.067^{* * *} \\
(0.006)\end{array}$ & $\begin{array}{c}0.067^{* * *} \\
(0.007)\end{array}$ & $\begin{array}{c}0.066^{* * *} \\
(0.006)\end{array}$ \\
\hline First floor of building ( $1=$ yes $)$ & $\begin{array}{c}0.005 \\
(0.013)\end{array}$ & $\begin{array}{c}0.022 \\
(0.016)\end{array}$ & & $\begin{array}{c}0.012 \\
(0.011)\end{array}$ & $\begin{array}{l}0.018^{*} \\
(0.010)\end{array}$ \\
\hline Top floor of building ( $1=$ yes $)$ & $\begin{array}{c}-0.066^{* * *} \\
(0.010)\end{array}$ & $\begin{array}{c}-0.072^{* * *} \\
(0.015)\end{array}$ & & $\begin{array}{c}-0.099^{* * *} \\
(0.014)\end{array}$ & $\begin{array}{c}-0.080^{* * *} \\
(0.010)\end{array}$ \\
\hline Project size (log) & $\begin{array}{c}0.003 \\
(0.008)\end{array}$ & $\begin{array}{c}-0.012 \\
(0.013)\end{array}$ & $\begin{array}{l}-0.004 \\
(0.008)\end{array}$ & $\begin{array}{l}-0.003 \\
(0.009)\end{array}$ & $\begin{array}{c}0.004 \\
(0.007)\end{array}$ \\
\hline Purchase-completion year bins & Yes & Yes & Yes & Yes & Yes \\
\hline 3-digit zip code fixed effects & Yes & Yes & Yes & Yes & Yes \\
\hline Larger land parcel fixed effect & Yes & Yes & Yes & Yes & Yes \\
\hline Purchase year fixed effects & Yes & Yes & Yes & Yes & Yes \\
\hline Quarter-of-year fixed effects & Yes & Yes & Yes & Yes & Yes \\
\hline$\overline{\mathrm{R}^{2}}$ & 0.872 & 0.852 & 0.858 & 0.853 & 0.861 \\
\hline Observations & 38,681 & 38,082 & 153,235 & 122,197 & 175,630 \\
\hline Number of regressors & 207 & 70 & 222 & 207 & 207 \\
\hline Dependent variable mean & 9.383 & 9.387 & 9.366 & 9.290 & 9.336 \\
\hline
\end{tabular}

Notes: ${ }^{* * *} \mathrm{p}<0.01,{ }^{* *} \mathrm{p}<0.05,{ }^{*} \mathrm{p}<0.1$. The dependent variable is the logarithm of the property's transaction price divided by the size of the unit (in January $2014 \mathrm{~S} \$$ per $\mathrm{m}^{2}$ ). See the notes to Table 2 for variable definitions. OLS regressions. Standard errors, in parentheses, are clustered by building and purchase year. Column (1) considers purchases of any lease type within $0.5 \mathrm{~km}$ of a development project for which we observe transactions of 825 to 986 -year leases. Column (2) considers purchases of any lease type but only in 3-digit zip codes with recorded sales of both 825 to 986-year leases and at least one other tenure type. Column (3) drops purchases of properties on the top and first floors. Column (4) drops purchases of units that were still under construction at the end of our sample period. Column (5) trims observations with very low or very high prices, defined as either the bottom or top $1 \%$ of the transaction price for each of the three lease types. 


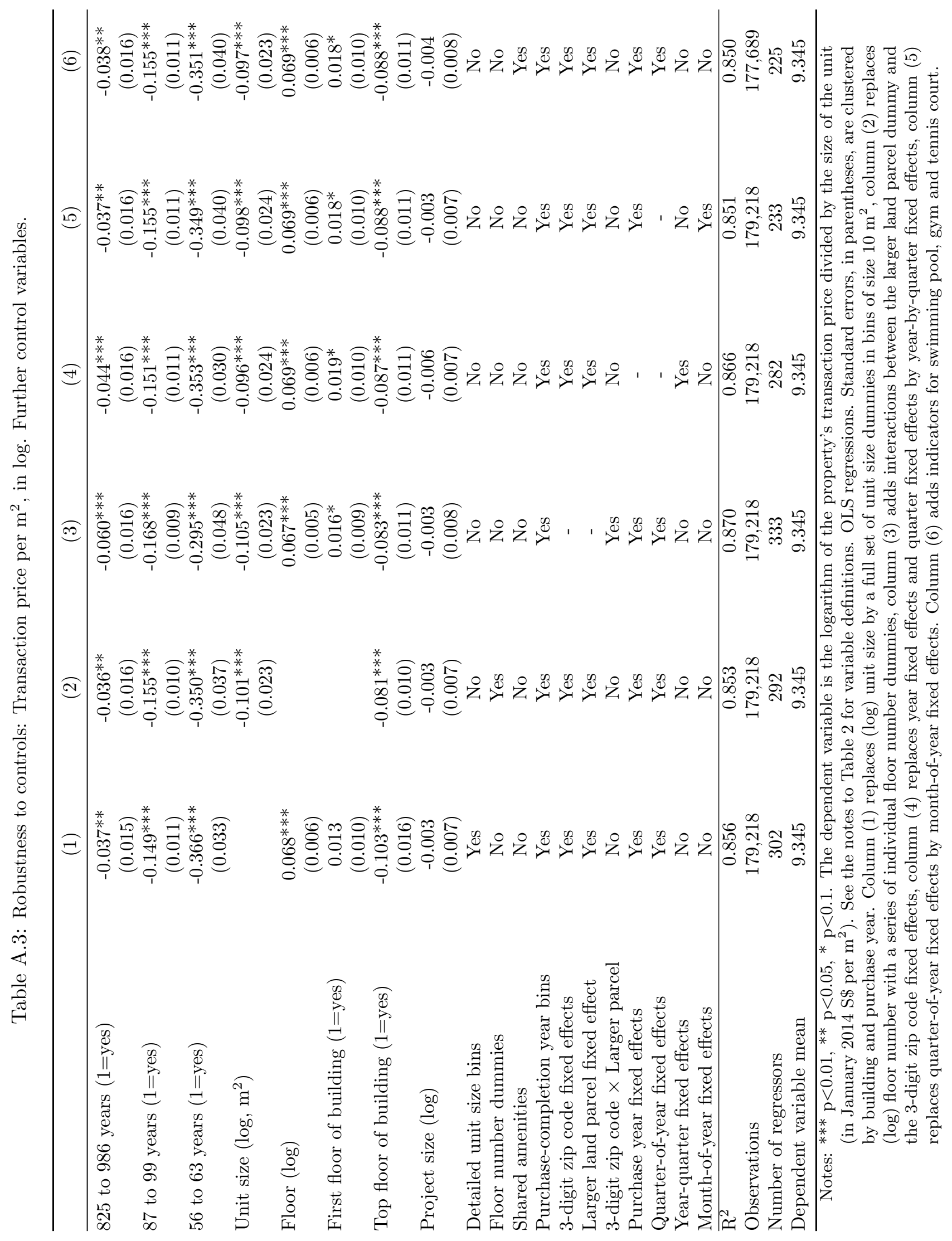


Table A.4: Monthly rental price per $\mathrm{m}^{2}$, in $\log$.

\begin{tabular}{lc}
\hline 825 to 986 years $(1=$ yes $)$ & -0.012 \\
87 to 99 years $(1=$ yes $)$ & $0.017)$ \\
& 0.010 \\
Age & $(0.046)$ \\
& -0.006 \\
Highest floor of the project $(\log )$ & $(0.008)$ \\
& $0.024^{*}$ \\
Project size $(\log )$ & $(0.012)$ \\
& 0.012 \\
Number-of-bedroom bins & $0.009)$ \\
3-digit zip code fixed effects & Yes \\
Larger land parcel fixed effect & Yes \\
Contract year fixed effects & Yes \\
Quarter-of-year fixed effects & Yes \\
\hline $\mathrm{R}^{2}$ & Yes \\
Observations & 0.774 \\
Number of regressors & 6,649 \\
Dependent variable mean & 40 \\
\hline
\end{tabular}

Freehold
825 to 986 years $\begin{gathered}\text { Sample frequency distribution } \\ \text { of rental contracts by } \\ \text { ownership tenure type }\end{gathered}$
87 to 99 years
Total $\quad \begin{aligned} & 4,792 \\ & 1,489 \\ & \text { Notes: } * * * \text { p }<0.01, * * \mathrm{p}<0.05, * \text { p }<0.1 . \text { The dependent variable is the logarithm of monthly rent per } \mathrm{m}^{2} \text { (in } \\ & \text { January } 2014 \mathrm{~S} \$) \text {. The sample consists of rental contracts between February } 2012 \text { and January } 2015 \text { for }\end{aligned}$
properties aged at most five years, and located in 3-digit zip codes with rental contracts recorded for
original $999-$ year leaseholds and at least one other lease type over the three-year sample period; we also
drop one-bedroom contracts (which include the renting out of a single bedroom) and trim the top and
bottom $1 \%$ of the rental price distribution. We do not observe the floor of the rented unit, and roughly
proxy for this using the highest floor across buildings in the project. Due to data restrictions, bedroom
bins consist of two dummy variables, three bedrooms and four-or-more bedrooms. See the notes to Table
2 for other variable definitions. OLS regressions. Standard errors, in parentheses, are clustered by project
and contract year.


Table A.5: Reproduction of the GMS sample for Singapore (January 1995 to December 2013).

\begin{tabular}{lrrrrrrrr}
\hline & & \multicolumn{7}{c}{ Share of transactions by remaining lease } \\
\cline { 3 - 9 } Purchase year & $\mathrm{N}$ & $21-69$ & $70-84$ & $85-89$ & $90-94$ & $95-101$ & $800-994$ & Freehold \\
\hline 1995 & 10,821 & 0.000 & 0.037 & 0.032 & 0.012 & 0.298 & 0.086 & 0.535 \\
1996 & 16,765 & 0.001 & 0.023 & 0.022 & 0.028 & 0.326 & 0.145 & 0.455 \\
1997 & 11,533 & 0.001 & 0.042 & 0.001 & 0.049 & 0.473 & 0.065 & 0.370 \\
1998 & 12,365 & 0.001 & 0.024 & 0.000 & 0.033 & 0.608 & 0.046 & 0.288 \\
1999 & 19,394 & 0.001 & 0.032 & 0.000 & 0.113 & 0.315 & 0.083 & 0.455 \\
2000 & 10,994 & 0.007 & 0.043 & 0.003 & 0.220 & 0.188 & 0.087 & 0.451 \\
2001 & 10,705 & 0.004 & 0.028 & 0.015 & 0.176 & 0.378 & 0.036 & 0.364 \\
2002 & 16,657 & 0.003 & 0.024 & 0.014 & 0.182 & 0.313 & 0.057 & 0.405 \\
2003 & 9,268 & 0.006 & 0.043 & 0.037 & 0.250 & 0.175 & 0.057 & 0.433 \\
2004 & 10,693 & 0.007 & 0.036 & 0.053 & 0.198 & 0.132 & 0.052 & 0.523 \\
2005 & 15,459 & 0.013 & 0.031 & 0.062 & 0.169 & 0.113 & 0.047 & 0.566 \\
2006 & 22,352 & 0.008 & 0.036 & 0.079 & 0.159 & 0.093 & 0.054 & 0.571 \\
2007 & 36,792 & 0.009 & 0.040 & 0.133 & 0.142 & 0.093 & 0.072 & 0.510 \\
2008 & 13,025 & 0.010 & 0.057 & 0.170 & 0.110 & 0.128 & 0.066 & 0.460 \\
2009 & 31,528 & 0.010 & 0.054 & 0.111 & 0.102 & 0.168 & 0.070 & 0.484 \\
2010 & 36,923 & 0.010 & 0.083 & 0.101 & 0.155 & 0.141 & 0.052 & 0.458 \\
2011 & 34,547 & 0.008 & 0.084 & 0.072 & 0.228 & 0.194 & 0.038 & 0.376 \\
2012 & 38,356 & 0.014 & 0.081 & 0.038 & 0.299 & 0.215 & 0.035 & 0.318 \\
2013 & 26,362 & 0.011 & 0.058 & 0.030 & 0.366 & 0.256 & 0.035 & 0.243 \\
Total & 384,539 & 0.008 & 0.052 & 0.062 & 0.172 & 0.217 & 0.059 & 0.430 \\
\hline & & & & & & & &
\end{tabular}

State of the purchased unit

Building of unit

being purchased

New Used Total

$\begin{array}{lccc}\text { Condominium } & 199,287 & 120,927 & 320,214 \\ \text { "Executive Condominium" } & 20,048 & 6,155 & 26,203 \\ \text { House } & 12,093 & 26,029 & 38,122 \\ \text { Total } & 231,428 & 153,111 & 384,539\end{array}$

Characteristics of the buyer according to his/her address at the time of purchase

The buyer currently lives in:

\begin{tabular}{lcccc}
\cline { 2 - 5 } $\begin{array}{l}\text { Building of unit } \\
\text { being purchased }\end{array}$ & $\begin{array}{c}\text { HDB } \\
\text { apartment }\end{array}$ & $\begin{array}{c}\text { Condominium } \\
\text { apartm./house }\end{array}$ & $\begin{array}{c}\text { Not } \\
\text { available }\end{array}$ & Total \\
\hline Condominium & 130,240 & 188,101 & 1,873 & 320,214 \\
"Executive Condominium" & 20,698 & 5,353 & 152 & 26,203 \\
House & 12,278 & 25,227 & 617 & 38,122 \\
Total & 163,216 & 218,681 & 2,642 & 384,539 \\
\hline
\end{tabular}

Notes: Includes all private property transaction between January 1995 and December 2013 with a lodged caveat. Despite its local name, an "executive condominium" is a higher-quality apartment whose purchase faces similar restrictions and subsidies as a regular HDB apartment (and is sometimes referred to as an HBD executive condominium). 


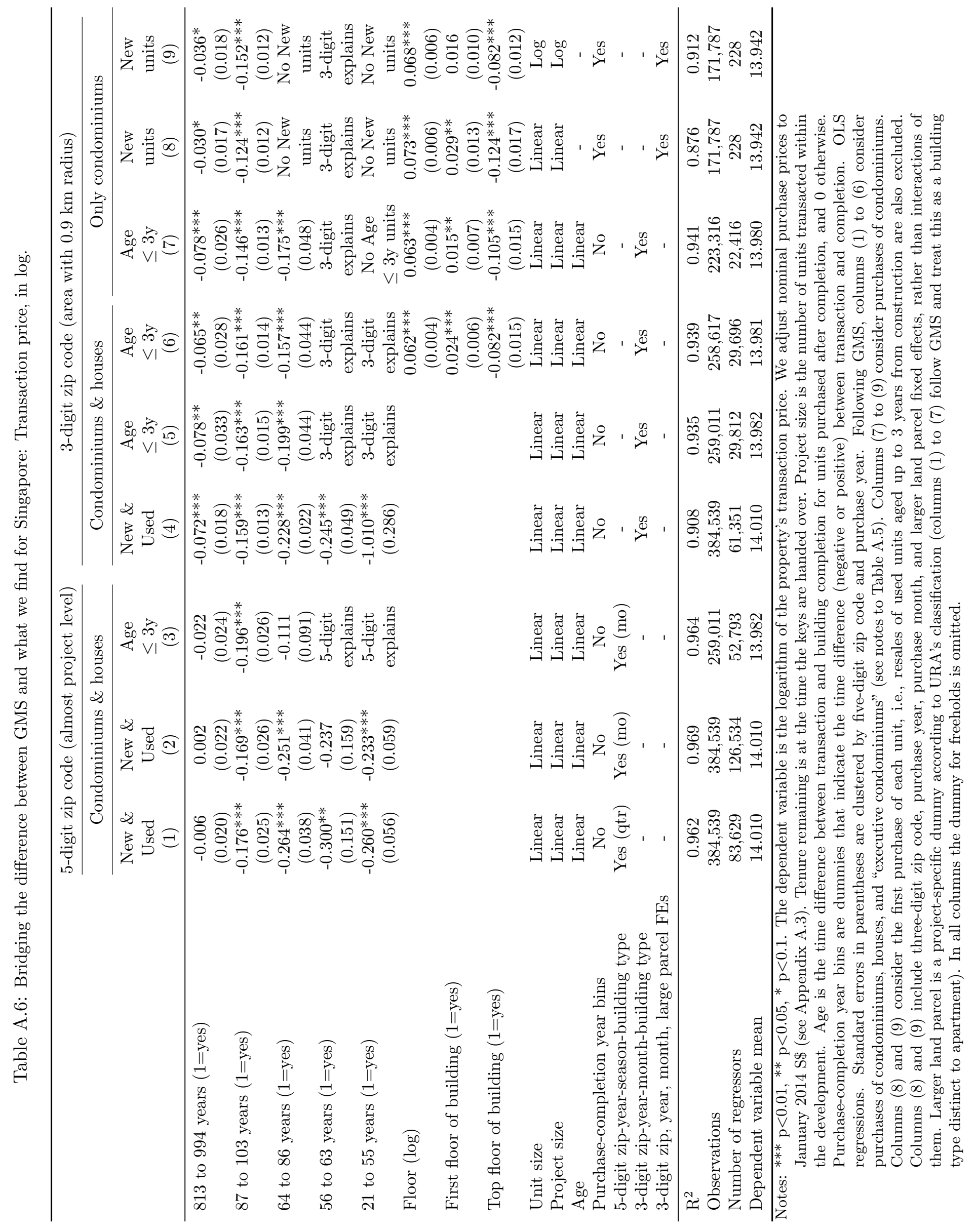




\section{References}

Aleshire, I. (1986, October). Land acquisition act to be amended, says ministry. The Straits Times.

Arrow, K. J., Cropper, M. L., Gollier, C., Groom, B., Heal, G. M., Newell, R. G., Nordhaus, W. D., Pindyck, R. S., Pizer, W. A., Portney, P. R., Sterner, T., Tol, R. S. J., and Weitzman, M. L. (2012). How should benefits and costs be discounted in an intergenerational context? Resources for the Future Discussion Paper 12-53.

Arrow, K. J., Cropper, M. L., Gollier, C., Groom, B., Heal, G. M., Newell, R. G., Nordhaus, W. D., Pindyck, R. S., Pizer, W. A., Portney, P. R., Sterner, T., Tol, R. S. J., and Weitzman, M. L. (2013). Determining benefits and costs for future generations. Science, 341(6144), pp. 349-350.

Arrow, K. J., Cropper, M. L., Gollier, C., Groom, B., Heal, G. M., Newell, R. G., Nordhaus, W. D., Pindyck, R. S., Pizer, W. A., Portney, P. R., Sterner, T., Tol, R. S. J., and Weitzman, M. L. (2014). Should governments use a declining discount rate in project analysis? Review of Environmental Economics and Policy, 8(2), pp. 145-163.

Bracke, P., Pinchbeck, T., and Wyatt, J. (2015). The time value of housing: Historical evidence on discount rates. SERC Discussion Paper 168.

Cline, W. R. (1992). The Economics of Global Warming. Institute for International Economics, Washington, D.C.

Cropper, M. L., Freeman, M. C., Groom, B., and Pizer, W. A. (2014). Declining discount rates. American Economic Review, 104(5): pp. 538-543.

Drupp, M., Freeman, M., Groom, B., and Nesje, F. (2015). Discounting disentangled. Centre for Climate Change Economics and Policy Working Paper 195.

Freeman, M. C., Groom, B., Panopoulou, E., and Pantelidis, T. (2015). Declining discount rates and the Fisher Effect: Inflated past, discounted future? Journal of Environmental Economics and Management, 73, pp. 32-49.

Fry, M. J. and Mak, J. (1984). Is land leasing a solution to unaffordable housing? Economic Inquiry, XXII: pp. 529-549.

Gautier, P. A. and van Vuuren, A. (2014). The estimation of present bias and time preferences using land-lease contracts. Mimeo, VU University of Amsterdam.

Giglio, S., Maggiori, M., and Stroebel, J. (2015). Very long-run discount rates. Quarterly Journal of Economics, 130(1): pp. 1-53.

Giglio, S., Maggiori, M., Stroebel, J., and Weber, A. (2015). Climate change and long-run discount rates: Evidence from real estate. Mimeo, University of Chicago.

Gollier, C. (2002). Discounting an uncertain future. Journal of Public Economics, 85(2): pp. $149-166$. 
Gollier, C. (2008). Discounting with fat-tailed economic growth. Journal of Risk and Uncertainty, 37(2): pp. 171-186.

Gollier, C. (2014). Discounting and growth. American Economic Review, 104(5): pp. 534-537.

Gollier, C. and Weitzman, M. L. (2010). How should the distant future be discounted when discount rates are uncertain? Economics Letters, 107: pp. 350-353.

Greenstone, M., Kopits, E., and Wolverton, A. (2011). Estimating the Social Cost of Carbon for use in U.S. federal rulemakings: A summary and interpretation. NBER Working Paper 16913.

Groom, B., Hepburn, C., Koundouri, P., and Pearce, D. (2005). Declining discount rates: The long and the short of it. Environmental \& Resource Economics, 32: pp. 445-493.

Groom, B., Koundouri, P., Panopoulou, E., and Pantelidis, T. (2004). Discounting the distant future: How much does model selection affect the certainty equivalent rate? Working Paper.

Groom, B., Koundouri, P., Panopoulou, E., and Pantelidis, T. (2007). Discounting the distant future: How much does model selection affect the certainty equivalent rate? Journal of Applied Econometrics, 22: pp. 641-656.

HM Treasury (2003). The Green Book: Appraisal and Evaluation in Central Government. HM Treasury, London.

Interagency Working Group on Social Cost of Carbon (2010, February). Social Cost of Carbon for Regulatory Impact Analysis under Executive Order 12866.

Lebègue, D. (2005). Révision du Taux d'Actualisation des Investissements Publics. Rapport du Groupe d'Experts, Commisariat général du Plan.

Lornie, J. (1921). Land tenure. In Makepeace, W., Brooke, G. E., and Braddell, R. S. J., editors, One hundred years of Singapore, vol. 1, ch. V, pp. 301-314. Oxford University Press, London.

Newell, R. G. and Pizer, W. A. (2003). Discounting the distant future: how much do uncertain rates increase valuations? Journal of Environmental Economics and Management, 46, pp. 52-71.

Nordhaus, W. D. (1994). Managing the Global Commons: The Economics of Climate Change. MIT Press, Cambridge, MA.

Nordhaus, W. D. (2007a). A review of The Stern Review on the Economics of Climate Change. Journal of Economic Literature, 45(3), pp. 686-702.

Nordhaus, W. D. (2007b). Critical assumptions in the Stern Review on the Economics of Climate Change. Science, 317(5835), pp. 201-202.

Office of Management and Budget, OMB (2003, September). Circular A-4: Regulatory Analysis.

Phang, S. Y. and Kim, K. (2011). Singapore's housing policies: 1960-2013. In Frontiers in Development Policy: Innovative Development Case Studies 123. KDI School and World Bank Institute. 
Singapore Department of Statistics. (2015). Singapore in Figures. Singapore Department of Statistics.

Stern Review (2007). The Economics of Climate Change: The Stern Review. Cambridge University Press, Cambridge.

Stern, N. and Taylor, C. (2007). Climate change: Risk, ethics, and the Stern Review. Science, $317(5835)$, pp. 203-204.

Stern, N. (2013). The structure of economic modeling of the potential impacts of climate change: Grafting gross underestimation of risk onto already narrow science models. Journal of Economic Literature, 51(3), pp. 838-859.

Sunstein, C. R. (2014). On not revisiting official discount rates: Institutional inertia and the social cost of carbon. American Economic Review, 104(5): pp. 547-551.

Taylor Wessing. (2012). Real Estate Finance in Singapore, Part 1 - Land Law in Singapore. Taylor Wessing.

Weitzman, M. L. (1998). Why the far-distant future should be discounted at its lowest possible rate. Journal of Environmental Economics and Management, 36(3): pp. 201-208.

Weitzman, M. L. (2001). Gamma discounting. American Economic Review, 91(1): pp. 260-271.

Weitzman, M. L. (2007a). A review of The Stern Review on the Economics of Climate Change. Journal of Economic Literature, 45(3): pp. 703-724.

Weitzman, M. L. (2007b). Subjective expectations and asset return puzzles. American Economic Review, 97(4): pp. 1102-1130.

Weitzman, M. L. (2013). Tail-hedge discounting and the social cost of carbon. Journal of Economic Literature, 51(3), pp. 873-882.

Wong, S. K., Chau, K. W., Yiu, C. Y., and Yu, M. K. W. (2008). Intergenerational discounting: A case from Hong Kong. Habitat International, 32: pp. 283-292. 